\title{
Monitoring immune modulation by nutrition in the general population: identifying and substantiating effects on human health
}

Ruud Albers ${ }^{1}$, Raphaëlle Bourdet-Sicard ${ }^{2}$, Deborah Braun ${ }^{3}$, Philip C. Calder ${ }^{4}$, Udo Herz ${ }^{5}$, Claude Lambert ${ }^{6}$, Irene Lenoir-Wijnkoop ${ }^{7}$, Agnès Méheust ${ }^{8}$, Arthur Ouwehand ${ }^{9}$, Phoukham Phothirath ${ }^{10}$, Tomoyuki Sako ${ }^{11}$, Seppo Salminen ${ }^{12}$, André Siemensma ${ }^{13}$, Henk van Loveren ${ }^{14}$ and Ulrich Sack ${ }^{15}$

1. NutriLeads, 3235 KT Rockanje, Netherlands; Host-Microbe Interactomics, Wageningen University, $6700 \mathrm{AH}$, Wageningen, The Netherlands

2. Danone Research, 91767 Palaiseau Cedex, France

3. Institut Mérieux, 69002 Lyon, France

4. Faculty of Medicine, University of Southampton, SO16 6YD, Southampton, UK

5. Mead Johnson Nutrition, 6454 CJ, Nijmegen, The Netherlands

6. Immunology Lab CHU Saint-Etienne, 42055 Saint Etienne Cedex 2, France

7. IDF - ILSI Liaison Officer, 91767 Palaiseau Cedex, France

8. ILSI Europe a.i.s.b.I., Avenue E. Mounier 83, Box 6, 1200 Brussels, Belgium

9. Active Nutrition, DuPont Nutrition and Health, 02460 Kantvik, Finland

10. Nestlé Research Center, Vers-chez-les-Blanc, 1000 Lausanne 26, Switzerland

11. Yakult Europe, 1332 EN, Almere, The Netherlands

12. Functional Foods Forum, University of Turku, 20014 Turku, Finland

13. FrieslandCampina, 8901 MA, Leeuwarden, The Netherlands

14. National Institute of Public Health and the Environment - RIVM, 3720 BA, Bilthoven, The Netherlands

15. Department of Diagnostics, Universität Leipzig, 04103 Leipzig, Germany 


\section{Table of Contents}

Paradigm relating immune function to health

Brief overview of major immune functions

Methodological and technical considerations

Criteria to select immune function markers

Selection and prioritisation of markers

Clustering of markers according to clinical relevance and involvement of immune functions

Scenarios to interpret changes in (sets of) markers

Beyond individual immune function markers

Conclusions and recommendations

Acknowledgements

Key words: Biomarkers: Immune function: Validation: Guidance: Criteria

Correspondence: ILSI Europe a.i.s.b.l., Avenue E. Mounier 83, Box 6 - 1200 Brussels, Belgium, fax +32 276200 44, email publications@ilsieurope.be

Abbreviations: CRP, C-reactive protein; DTH, delayed-type hypersensitivity; ILSI, International Life Sciences Institute; NK, natural killer; sIgE, specific IgE.

This paper was published as a supplement to British Journal of Nutrition, publication of which was supported by ILSI Europe. The paper has undergone the standard journal formal review process and may be cited.

(C) ILSI Europe [2013]. The online version of this paper is published within an Open Access environment subject to the conditions of the Creative Attribution-NonCommercial-ShareAlike licence $<$ http://creative commons.org/licenses/by-nc-sa/3.0/ $>$. The written permission of Cambridge University Press must be obtained for commercial re-use. 
Optimal functioning of the immune system is crucial to human health, and nutrition is one of the major exogenous factors modulating different aspects of immune function. Currently, no single marker is available to predict the effect of a dietary intervention on different aspects of immune function. To provide further guidance on the assessment and interpretation of the modulation of immune functions due to nutrition in the general population, International Life Sciences Institute Europe commissioned a group of experts from academia, government and the food industry to prepare a guidance document. A draft of this paper was refined at a workshop involving additional experts. First, the expert group defined criteria to evaluate the usefulness of immune function markers. Over seventy-five markers were scored within the context of three distinct immune system functions: defence against pathogens; avoidance or mitigation of allergy; control of low-grade (metabolic) inflammation. The most useful markers were subsequently classified depending on whether they by themselves signify clinical relevance and/or involvement of immune function. Next, five theoretical scenarios were drafted describing potential changes in the values of markers compared with a relevant reference range. Finally, all elements were combined, providing a framework to aid the design and interpretation of studies assessing the effects of nutrition on immune function. This stepwise approach offers a clear rationale for selecting markers for future trials and provides a framework for the interpretation of outcomes. A similar stepwise approach may also be useful to rationalise the selection and interpretation of markers for other physiological processes critical to the maintenance of health and well-being.

The overall aim of this article is to provide further guidance for the assessment and interpretation of immune modulation by nutrition in the general population. To this end, the European Branch of the International Life Sciences Institute (ILSI) established a group of experts from academia, government and the food industry to agree upon criteria to evaluate the usefulness of immune function markers in a structured manner. Over seventy-five markers were scored and evaluated within the context of three distinct domains of immune function: defence against pathogens; avoidance or mitigation of allergy; control of low-grade inflammation mainly focusing on metabolic inflammation. Other aspects of immune function such as autoimmunity and surveillance against tumours were not included at this stage. The most useful markers were classified depending on whether they by themselves demonstrate clinical relevance and/or involvement of immune function. In addition, five theoretical scenarios were drafted describing potential changes in the values of markers compared with a relevant reference range. These include (significant) modulation within the reference range (a very common scenario for modulation due to nutrition), modulation from outside the reference range back into the range, modulation from within the reference range out of the range, prevention of modulation induced by other factors, and modulation from a less favourable range to the reference range of a comparator group with a more desired immune function (e.g. from bottle-fed to breast-fed infants). Finally, the expert group combined all of the above-mentioned information, providing a framework to aid the design and interpretation of studies assessing the effects of nutrition on immune function. An early draft of this report was discussed with a wider group of experts at a workshop held in Nice, France, 16-17 April 2012. Additional information about the workshop discussions and participants is available on the ILSI Europe website (http://www.ilsi.org/Europe/Pages/HomePage.aspx).

The main function of the immune system is to help maintain homeostasis by providing protection against infections. On the other hand, inappropriate or improperly controlled immune functions contribute to pathophysiological processes such as allergic manifestations and chronic inflammatory responses. Development and maintenance of a normal immune system are thus essential for a healthy and active life. Functioning of the immune system is influenced by a variety of inherited, environmental, behavioural, social and individual factors ${ }^{(1)}$. Therefore, it is no surprise that solutions to help develop, restore or optimise immune functions are much sought after by scientists, consumers and industry alike.

One of the major modifiable factors affecting immune function is nutrition (the primary factor being vaccination); undernutrition is often related to decreased immune function, whereas overnutrition and obesity can contribute to chronic low-grade inflammatory changes. Whole diets, individual nutrients and food components such as phytochemicals, prebiotics and probiotics have all been shown to influence distinct aspects of the immune system. These effects have been reviewed extensively in a number of recent papers ${ }^{(2-21)}$ Several other papers have provided some guidance on how best to assess specific immune functions and which confounding factors and methodological aspects to consider ${ }^{(1,18,22-28)}$ Moreover, the European Food Safety Authority panel on dietetic products, nutrition and allergies has recently issued a guidance document on the scientific requirements for the substantiation of health claims related to gut and immune function $^{(29)}$. This document offers an excellent starting point for the assessment and interpretation of immune modulation by nutrition. However, some critical elements are still missing, and especially when focusing on the assessment and optimisation of immune function in the general population, some questions remain largely unanswered. These include the following: (1) How can 'optimal immune function(s)' be identified and characterised? (2) Which markers are most informative to describe (optimal) immune function(s)? (3) How can changes in the values of these markers be interpreted? (a) Can immune function(s) in a general population be optimised? (b) How to assess improved immune function(s)? (c) How to identify risk associated with the modulation of immune function(s)?

This article aims to provide some further guidance on these aspects by providing criteria for the selection of immune function markers, ranked lists of markers that best describe the (modulation of) specific immune functions in the general population, reference to normal values and ranges established in laboratory medicine and daily clinical practice for selected 
markers, and rational approaches for the design of studies, selection of markers and interpretation of changes observed in these markers due to exogenous factors such as nutrition.

\section{Paradigm relating immune function to health}

The basic paradigm of the relationship between immune function and health is illustrated in Fig. 1. Regardless of the marker or assay used, immune functions vary between subjects and they fluctuate over time within a subject. In a healthy population, these fluctuations define the boundaries of a 'normal range', and immune function(s) within this 'homeodynamic bandwidth' are postulated to support the maintenance of 'optimal health'. Genetic make-up and past experiences contribute to differences between subjects, and environmental or lifestyle-associated factors can temporarily or permanently move specific immune function(s) outside these ranges, thus failing to support optimal health. If this is sustained or becomes more extreme, it may contribute to pathogenic processes and modify disease risk. Within this paradigm, optimising immune function encompasses the return of such function(s) back into the normal range and/or strengthening of the resilience of the function(s), thus reducing the amplitude of fluctuations and reinforcing the homeodynamic regulation within the optimal range ${ }^{(2,30)}$. Consequently, at times, it may be beneficial to down-regulate hyperactive immune functions or up-regulate hypoactive immune functions or to strengthen the resilience of immune functions to respond to external 'stressors'.

\section{Brief overview of major immune functions}

The immune system helps to maintain homeostasis by mounting non-specific innate and specific adaptive responses against potentially pathogenic micro-organisms. At the same time, the immune system should tolerate self-antigens and innocuous non-self-antigens and allergens as uncontrolled or inappropriate responses to such antigens contribute to the pathogenic processes underlying various non-communicable diseases. Inappropriate or exaggerated immune responses to allergens lead to allergic manifestations such as allergic rhinitis (hay fever), allergic asthma, atopic dermatitis (eczema) and food allergy. Sustained responses to persistent antigens, such as autoantigens or those that are derived from commensal micro-organisms, lead to tissue remodelling and loss of function of the affected tissue and contribute to the symptoms of chronic inflammatory diseases such as rheumatoid arthritis, inflammatory bowel disease and psoriasis ${ }^{(2,31)}$. More recently, it has also become apparent that metabolic stresses (e.g. in visceral adipocytes of obese subjects) trigger low-grade asymptomatic inflammatory responses, which contribute to the comorbidity of metabolic disorders ${ }^{(32,33)}$.

These different aspects of immune function are highly relevant in the general population, affecting the maintenance of health and vitality. Immune function markers are, therefore, considered within the context of the following distinct physiological function domains of the immune system: defence against pathogens; avoidance or mitigation of allergy; reduction of asymptomatic low-grade metabolic inflammation.

Defence against pathogens relates to the physiological function of the immune system to deal with (common) pathogens such that the infection does not establish itself, or if it does, then with no or minimal symptoms. Avoidance or mitigation of allergy relates to the ability of the immune system to tolerate potentially allergenic substances without symptoms of allergy. The beneficial effects of nutrition on this activity could thus, in theory, lead to reduced sensitisation to an allergen or mitigation of the severity of allergic responses to non-food-related allergens such as respiratory or contact allergens and so are not necessarily restricted to food allergy. Reduction of asymptomatic low-grade inflammation relates to the ability of the immune system to control low-grade inflammatory responses that are triggered by metabolic stresses and that, if improperly controlled, become chronic and contribute to the pathophysiology of various diseases.

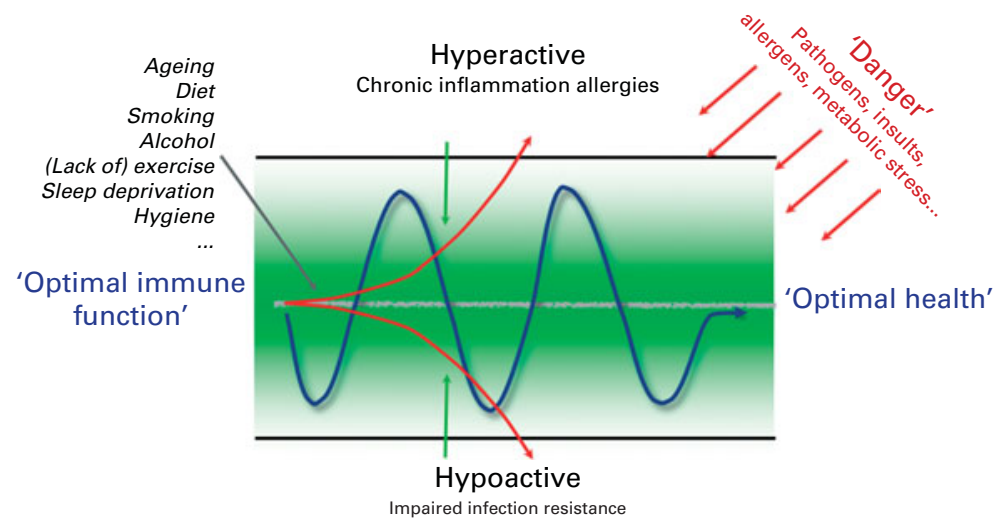

Fig. 1. Illustration of the general paradigm postulating that fluctuations within the boundaries of a normal range support the maintenance of optimal health. Regardless of the marker or assay used, immune functions vary between subjects and they fluctuate within subjects over time ( $\longrightarrow$ ), although apparently within some normal limits (green zone) that may be individually defined. Certain (combinations of) factors can drive immune function(s) to a state of hypo- or hyperactivity $(\longrightarrow)$. The objective of a (nutritional) intervention is to restore functions to the normal range ( $\longrightarrow$ ) and/or to strengthen the resilience of these function(s), reducing the amplitude of fluctuations and thus reinforcing the homeodynamic regulation within the normal range. Adapted from Hamer et al. ${ }^{(30)}$. 
To exert its functions, the immune system deploys a range of structural, cellular and molecular components. A wide variety of methods and markers are being used to measure the magnitude of variation of these immune functions. Such markers range from the assessment of clinical symptoms and integrated responses to particular in vivo challenges and ex vivo assessment of isolated functions of the immune system to more basic enumeration of a particular (sub)type of cell or measurement of the concentrations of specific factors without any defined challenge to the system. Building on a previous publication $^{(1)}$, we have classified the markers from the most integrated/physiologically relevant to the most isolated/mechanistically insightful as illustrated in Fig. 2.

It is acknowledged that new technologies, such as genomics, proteomics and so forth, are continuously being developed. Such techniques may, in the future, provide new biomarkers and also more insight into relevant intracellular responses. Future evaluation of such new biomarkers, however, can follow the same criteria as for the current biomarkers.

The following definitions are used in this work:

Symptom: sensation or change in bodily function or appearance experienced by a person that suggests a disorder or pathology (e.g. runny nose as a symptom of a respiratory infection or rhinitis and watery stool as a symptom of diarrhoea).

In vivo response: integrated response to a (standardised) in vivo challenge (e.g. response to vaccination, prick and patch tests or oral provocation test).

Ex vivo response: (nutritional) intervention or comparison occurring in vivo; cells or blood isolated from participants in a study is assayed for functionality using a defined in vitro challenge (e.g. phagocytosis, natural killer (NK) cell activity or production of cytokines by ex vivo stimulated peripheral blood mononuclear cells or whole blood).

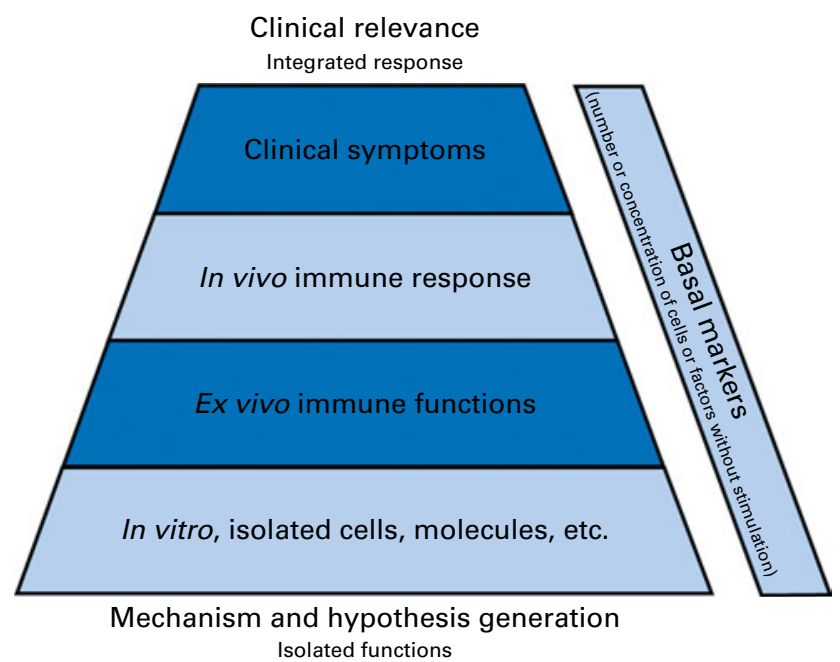

Fig. 2. Graphical representation indicating the classification of immune function markers from the most integrated/physiologically relevant to the most isolated/mechanistically insightful, with the basal markers being positioned on the side as they do not indicate a function by themselves, but aid in the interpretation of the functional markers.
In vitro response: (nutritional) intervention or comparison occurring in vitro; cells or blood isolated from subjects not participating in a study is exposed in vitro to the compounds, nutrients and so forth to be compared and is subsequently assayed for functionality using a defined in vitro challenge. This use of functional assays is intended not as a biomarker but rather as a tool for screening or mechanistic studies. This approach is outside the scope of the current activity.

Basal markers: cellular or molecular components of the immune system that are measured without a defined preceding challenge (e.g. cell types or cytokines). Not to be confused with the basal level (which is the actual value).

\section{Methodological and technical considerations}

Study design, randomisation and selection of appropriate control groups are critically important aspects when designing human studies for any outcome. Generic and more specific considerations for studies focusing on the effects of nutrition on immune function have been described in detail in earlier publications ${ }^{(1,23-25)}$. The effects of nutrition are potentially important in the longer term, but are typically modest and often difficult to observe in the short term. To assess these modest effects, it is important to carefully consider other factors known to influence immune function as these may otherwise obscure the effects of nutrition. Such confounders include stress $^{(34)}$, age ${ }^{(35,36)}$, sex ${ }^{(37)}$, ethnicity, physical fitness $^{(18)}$, ircadian $^{(38,39)}$ and seasonal ${ }^{(40)}$ influences, and sleep deprivation $^{(41)}$. Using carefully selected procedures for randomisation and clear criteria for (non)inclusion ${ }^{(42)}$, these confounders should be controlled for as much as possible. In some cases, they may also be used to select representative at-risk subpopulations to increase the sensitivity of the study. Examples of this include the selection of children from atopic parents ${ }^{(43)}$, children in day-care centres exposed to a high infection load ${ }^{(44)}$, people complying with specific exercise regimens ${ }^{(18)}$, shift workers ${ }^{(45)}$, people suffering from irritable bowel syndrome ${ }^{(46)}$ or food intolerances ${ }^{(47,48)}$, people with a BMI above a particular threshold ${ }^{(49)}$, elderly individuals above a particular age $\mathrm{s}^{(50)}$ and so forth. Although this can greatly increase the sensitivity of the study to detect modulation by nutrition, care should be taken that the selected subpopulation is still sufficiently representative of the general population to allow meaningful extrapolation. For the purpose of the current activity, we focus on the selection of markers of immune functions to assess the effects of nutrition in the general population assuming the use of properly controlled, well-designed observation or intervention studies that take all of these critical elements into account.

When selecting markers to assess effects on immune function, it is important to realise that the identification, development and (clinical) validation of markers are mostly done in the context of diseases. Whereas the relevance of particular markers for the diagnosis or prognosis of specific diseases may be well established, their relevance in a general population is typically less clear as very few prognostic studies have carefully assessed the predictive value of these markers 
for maintenance of health. Moreover, in the context of disease, markers are commonly used to determine the diagnosis or prognosis for individual patients. Based on a comparison of a patient's marker with a defined normal or reference range, conclusions are drawn for the individual patient. In contrast, in the context of nutritional effects in the general population, immune function markers are used to establish meaningful changes that occur at the group level. Typically, average (changes in) values of markers in one group are compared with (changes in) the values of markers in a control or reference group. This can be done observationally to assess associations between particular nutritional traits and immune functions or experimentally by applying a specific nutritional intervention in one of two groups to assess the impact of that intervention. In both cases, conclusions are drawn regarding the effect of the nutritional difference on immune function at the group level. Despite these differences between the use and interpretation of markers in the context of disease or in the context of the general population, essentially similar criteria apply when determining the usefulness of individual markers, although the relative weight of the individual criteria may be somewhat different.

In all cases, it should be clear as to what marker is measured and the assay used should measure it reliably; procedures and assays should be properly standardised and analytically validated. This includes the use of standardised operating procedures, including details of sampling, transport, storage and measurement of the analytes. Many analytes are sensitive to sampling conditions such as time during the day (circadian rhythm), fasting $v$. non-fasting, subject anxiety or stress level and even whether a blood sample is taken using a venepuncture or an indwelling catheter. Conditions for sample processing, transport and storage should, therefore, be clearly established and standardised, and the laboratory measurement should be analytically validated. This includes specificity, sensitivity, limit of detection, precision, robustness and linearity involving proper quality control and international gold standards if available. Several excellent papers have provided more specific information on the critical aspects of analytical validation and general laboratory quality management systems (e.g. EN ISO 15189 and EN ISO 17 025) or on those described in the good clinical laboratory practice guidelines ${ }^{(51-55)}$.

Some immune function markers such as C-reactive protein (CRP), differential cell counts or lymphocyte subset distributions are commonly used in clinical settings; for these properly validated procedures, assays and defined normal ranges and threshold values have been established (see, for instance, http://labtestsonline.org/). An example of reference ranges for lymphocyte subsets in different age groups has been given in several publications ${ }^{(56-59)}$. However, most of these markers are basal markers involving the enumeration of cells or factors in a sample without controlled experimental stimulation to assess a specific functional response. Such markers can aid the interpretation of more functional assays, but by themselves have limited value in nutrition studies, as they are rather insensitive to detect a modest modulation due to nutrition and are difficult to interpret in the general population. Unfortunately, more useful markers involving a functional response to a challenge such as in vivo challenge tests and ex vivo cellular function assays are much less standardised, have not been validated to the same extent and results can generally not be compared very well between laboratories. Moreover, assays and procedures involved are frequently tailored, for instance, by using suboptimal stimulation conditions (suboptimal concentration or incubation time) in ex vivo functional cell assays or by assessing responses after a suboptimal vaccination protocol (low level of adjuvant, low vaccine dose, only fraction of a multipledose antigen given, and assessment of the response during its early exponential phase). Although these modifications make good sense to increase the sensitivity and dynamic range to detect modulatory effects by avoiding saturation of the responses, they have led to a broad variety in protocols being used, many of which are not yet sufficiently standardised or validated to allow comparisons between different laboratories. There is a clear need for further standardisation and validation of these markers using protocols optimised to assess (alterations in) immune function in the general population. This should include further standardisation, analytical validation and ring testing between sites. Once this has been established, it will become more feasible to include such markers in prospective cohorts aiming to establish normal ranges and threshold values as well as their predictive values in the general population.

Normal ranges and thresholds are commonly used in clinical settings to interpret (changes in) markers of individual patients. Despite the different contexts and the limitations indicated above, essentially similar principles may be applied to devise a rational framework to aid the interpretation of nutritional effects on immune function at the group level in the general population. In the absence of more generically applicable normal ranges, (changes in) immune function markers are commonly compared with the following: the value of the markers in the same subjects before the intervention, the values of the markers in an appropriate control group matched for the most relevant criteria (age, sex, body weight, etc.) within the same study or combinations of the above (e.g. comparing the change within subjects between groups).

The strengths and limitations of these approaches have been discussed previously, and selection of the most appropriate reference group needs to be done on a case-by-case basis $^{(1,18,22-25,27)}$. Importantly, for markers without established normal ranges and threshold values, comparison with the reference range obtained in an appropriate control group can be used as the basis for the interpretation of effects. This can be done by using statistical significance after appropriate analysis to determine the threshold for relevance as discussed in more detail below.

\section{Criteria to select immune function markers}

As has been indicated above, a wide variety of markers can be used to assess different aspects of the immune system, and multiple assays based on diverse technical principles are often available. We aimed to define generic criteria to select 
the most useful markers. It is acknowledged that markers may respond in clusters or that ratios of different markers may be calculated. Such marker clusters or ratios have not been included (except for an example of an immune risk profile defined in elderly individuals) in order not to further increase the size of the tables. The reader can, however, compile such composite markers and assess their usefulness following the criteria set out below.

The criteria and scoring system used are based on the work by Albers et al. ${ }^{(1)}$ involving criteria that cover clinical relevance, biological sensitivity, feasibility and practical aspects for use in nutrition studies. Scores range from 0 to +++ , where +++ is the highest score for the most solid evidence. More details on the standardised scaling used for each of these criteria are provided in Table 1.

Because the analysis focuses on the evaluation and ranking of markers and not on assays used to measure these markers, criteria for analytical validation were not included. Instead, it was assumed that markers are assessed using the optimal assay, according to the relevant standards discussed in the following sections on methodological and technical considerations and the selection and prioritisation of markers. In addition, whether a marker has previously been shown to be sensitive to nutrition was not included as a criterion because this is severely confounded by what has been tried and does not help to assess the intrinsic usefulness of a marker to define the (modulation) of immune function. However, when designing a specific study, it would be wise to consider the possibility that a particular marker is modulated by that particular nutritional modification (e.g. based on existing data or on mechanistic insights). The criteria that were selected to evaluate the generic usefulness of markers can be grouped into three clusters: clinical relevance; biological sensitivity; feasibility. In addition, practical aspects including costs and logistic implications were scored because these are important aspects to know; however, as these are nonscientific arguments that may weigh very differently in different settings, these practicalities were not included in the integrative assessment of the overall usefulness of the markers.

\section{Clinical relevance}

Clinical relevance is the weight that one would give to a specific biomarker to reflect an immune system-mediated clinically detectable health status in the general population

Differentially expressed in normal and high-risk individuals. This criterion should be linked to the different functional domains (defence against pathogens, allergens and inflammation). Scores given in Tables 2 and 3 are for the functional domain for which the marker has most relevance. While the level of a given marker may be important, the way it is measured is also relevant because the evaluation can be made based on single measurements as well as the kinetics of a marker response. Markers without any known or anticipated relevance for the general population are outside the scope of this article (e.g. specific leucocyte tumour markers).

Correlates with relevant clinical endpoint. Note that correlation does not necessarily imply causality. Markers without a known correlation with a given immunological function/status for the general population are outside the scope of this work for further evaluation.

Experimentally linked to causal pathway. The markers rating the highest would be those for which proof of causality has been clearly established using human data.

Biological sensitivity. Biological sensitivity is the level to which the marker is influenced by and linked to the biological process. This factor is highly influenced by the 'normal' interand intra-subject variation as well as by the amplitude of the studied effect. A distinction is made between explainable variation and unexplainable variation; it is assumed that it would be possible to (partially) correct for the former.

Reasonable within-subject variation. The higher the within-subject variation, the larger the number of subjects required to observe an effect within a subject and the lower the score. As many immune function markers have (substantially) lower intra- than inter-subject variation, comparison of changes within subjects between groups (instead of comparing individual measurements per subject) often helps to increase sensitivity to detect effects.

Reasonable/explainable between-subject variation. The higher the between-subject variation, the larger the number of subjects required to observe an effect between groups and the lower the score.

Feasibility. Feasibility pertains to how feasible/practical it is to measure the biomarker.

Technical feasibility. The sensitivity of the assay available should be sufficient to detect the effect. The assay can be used repeatedly if needed (e.g. no saturation of response as with vaccination). The criteria include aspects such as stability of the marker, storage of the sample (storage possible $v$. need to work with fresh material), limitations of sample transportation, level of preanalytical processing and so forth.

Robustness. This criterion makes a general assessment of the precision and accuracy of the best assay available to measure a given marker. This reflects the level of variation between assays performed by different people, with different instruments (if relevant) or in different laboratories as well as the degree of uncertainty about the result obtained. The best score is given to a standardised assay with an acceptable CV that enables the detection of the expected effect size. This is reflected by approval or non-approval by regulatory authorities and/or wide distribution. Note that an assay only used in a single research laboratory can be very robust, but strong evidence would not be accessible to prove so.

Practicality. Practicality pertains to how practically feasible it is to measure the biomarker in nutrition studies Although cost and logistic aspects involved in the assessment of particular markers affect the feasibility to include markers in particular studies, these aspects were not taken into consideration when determining the overall usefulness of a marker, which was based on scientific criteria. As these practical aspects are nonetheless very important, a score is provided for information based on aspects such as the number of visits the subject is required to make, the availability and cost of the assay, the degree of expertise needed to perform the assay and so forth. 
Table 1. Criteria for the evaluation of markers

\begin{tabular}{|c|c|c|c|c|c|c|c|c|}
\hline \multirow[b]{2}{*}{ Levels } & \multicolumn{3}{|c|}{ Clinical relevance } & \multicolumn{2}{|c|}{ Biological sensitivity } & \multicolumn{2}{|c|}{ Feasibility } & \multirow[b]{2}{*}{ Practicality } \\
\hline & $\begin{array}{l}\text { Differentially } \\
\text { expressed }\end{array}$ & $\begin{array}{l}\text { Correlates with } \\
\text { clinical endpoint }\end{array}$ & $\begin{array}{l}\text { Linked to causal } \\
\text { pathway }\end{array}$ & $\begin{array}{l}\text { Within-subject } \\
\text { variation }\end{array}$ & $\begin{array}{l}\text { Between-subject } \\
\text { variation }\end{array}$ & Technical & Robustness & \\
\hline $\begin{array}{l}\text { Proven } \\
(+++)\end{array}$ & $\begin{array}{l}\text { Reproducibly } \\
\text { proven association } \\
\text { of differential } \\
\text { expression with } \\
\text { differential risk }\end{array}$ & $\begin{array}{l}\text { Generally accepted } \\
\text { as a risk factor } \\
\text { (correlation with } \\
\text { onset/resolution of } \\
\text { the clinical endpoint) }\end{array}$ & $\begin{array}{l}\text { Proven explanation } \\
\text { backed by human } \\
\text { data }\end{array}$ & $\begin{array}{l}\text { Minimal variation and } \\
\text { relevant effects highly } \\
\text { superior to variation: } \\
\text { effects likely to be } \\
\text { observed between } \\
\text { groups of tens of } \\
\text { people }\end{array}$ & $\begin{array}{l}\text { Minimal variation and } \\
\text { relevant effects highly } \\
\text { superior to variation: } \\
\text { effects likely to be } \\
\text { observed between } \\
\text { groups of tens of } \\
\text { people }\end{array}$ & $\begin{array}{l}\text { Marker is stable and } \\
\text { validated and highly } \\
\text { available assay and } \\
\text { can easily be done } \\
\text { repeatedly with high } \\
\text { throughput (e.g. CRP) }\end{array}$ & $\begin{array}{l}\text { Approved diagnos- } \\
\text { tic test available } \\
\text { (IVD; e.g. CE } \\
\text { marked or FDA } \\
\text { approved) }\end{array}$ & $\begin{array}{l}\text { Minimally invasive, } \\
\text { done at bedside } \\
\text { (a general practitioner } \\
\text { can do it) (e.g. symp- } \\
\text { toms, faeces, urine } \\
\text { and saliva) - single } \\
\text { interaction with the } \\
\text { subject }\end{array}$ \\
\hline $\begin{array}{l}\text { Strong } \\
(++)\end{array}$ & $\begin{array}{l}\text { Direct evidence } \\
\text { linking differential } \\
\text { response to } \\
\text { differential risk } \\
\text { (e.g. vaccination) }\end{array}$ & $\begin{array}{l}\text { Described as a } \\
\text { cause and effect } \\
\text { relationship, but } \\
\text { not (yet) generally } \\
\text { accepted as a risk } \\
\text { factor, needs more } \\
\text { studies or not } \\
\text { specific }\end{array}$ & $\begin{array}{l}\text { Plausible mechan- } \\
\text { istic hypothesis } \\
\text { with some human } \\
\text { data }\end{array}$ & $\begin{array}{l}\text { High variation explain- } \\
\text { able (e.g. circadian } \\
\text { cycle) and possible to } \\
\text { correct it and relevant } \\
\text { effects reproducibly } \\
\text { superior to variation: } \\
\text { effects likely to be } \\
\text { observed between } \\
\text { groups of fifties to } \\
\text { hundreds of people }\end{array}$ & $\begin{array}{l}\text { High variation explain- } \\
\text { able (e.g. age, sex, } \\
\text { BMI, ethnicity and } \\
\text { genotype) and poss- } \\
\text { ible to correct it with } \\
\text { stratification and } \\
\text { relevant effects repro- } \\
\text { ducibly superior to } \\
\text { variation: effects likely } \\
\text { to be observed } \\
\text { between groups of } \\
\text { fifties to hundreds } \\
\text { of people }\end{array}$ & $\begin{array}{l}\text { Sample can easily } \\
\text { be made stable and } \\
\text { limited processing } \\
\text { (e.g. preparation of } \\
\text { PBMC), or sample } \\
\text { can be refrigerated } \\
\text { for a limited time } \\
\text { (e.g. ELISA of } \\
\text { cytokines) }\end{array}$ & $\begin{array}{l}\text { Service commer- } \\
\text { cially available in } \\
\text { accredited labora- } \\
\text { tories (e.g. LDT } \\
\text { through CLIA } \\
\text { laboratories in } \\
\text { the USA) }\end{array}$ & $\begin{array}{l}\text { Somewhat invasive } \\
\text { (blood sample) - may } \\
\text { require several inter- } \\
\text { actions with the } \\
\text { subject (vaccination, } \\
\text { skin prick test, etc.) } \\
\text { and sample sent to } \\
\text { a laboratory }\end{array}$ \\
\hline $\begin{array}{l}\text { Medium } \\
(+)\end{array}$ & $\begin{array}{l}\text { Indirect evidence } \\
\text { linking a change in } \\
\text { function to a change } \\
\text { in risk }\end{array}$ & $\begin{array}{l}\text { Body of evidence } \\
\text { suggesting corre- } \\
\text { lation, but cause and } \\
\text { effect not established }\end{array}$ & $\begin{array}{l}\text { Plausible mecha- } \\
\text { nistic hypothesis } \\
\text { backed by animal } \\
\text { data }\end{array}$ & $\begin{array}{l}\text { High variation explain- } \\
\text { able (e.g. circadian } \\
\text { cycle) and possible to } \\
\text { correct it and relevant } \\
\text { effects reproducibly } \\
\text { close to variation: } \\
\text { effects may be } \\
\text { observed between } \\
\text { groups of fifties to } \\
\text { hundreds of people }\end{array}$ & $\begin{array}{l}\text { High variation explain- } \\
\text { able (e.g. age, sex, } \\
\text { BMI, ethnicity and } \\
\text { genotype) and poss- } \\
\text { ible to correct it with } \\
\text { stratification and rel- } \\
\text { evant effects reprodu- } \\
\text { cibly close to } \\
\text { variation: effects may } \\
\text { be observed between } \\
\text { groups of fifties to } \\
\text { hundreds of people }\end{array}$ & $\begin{array}{l}\text { Sample needs to be } \\
\text { frozen, or assay can } \\
\text { only be done once } \\
\text { (e.g. response to } \\
\text { vaccination) }\end{array}$ & $\begin{array}{l}\text { Commercially } \\
\text { available RUO kits }\end{array}$ & $\begin{array}{l}\text { Expert and/or expens- } \\
\text { ive material needed } \\
\text { (MRI, X-ray and } \\
\text { routine flow } \\
\text { cytometry) }\end{array}$ \\
\hline Low (0) & $\begin{array}{l}\text { Plausible hypothesis } \\
\text { with supporting } \\
\text { animal data }\end{array}$ & $\begin{array}{l}\text { Plausible hypothesis, } \\
\text { in use as an explora- } \\
\text { tory marker, but no } \\
\text { substantial body of } \\
\text { evidence (yet) }\end{array}$ & $\begin{array}{l}\text { Plausible mechan- } \\
\text { istic hypothesis } \\
\text { backed only by } \\
\text { in vitro data }\end{array}$ & $\begin{array}{l}\text { High and unexplained } \\
\text { variation in a short } \\
\text { time span and rel- } \\
\text { evant effects likely to } \\
\text { be observed between } \\
\text { groups of thousands } \\
\text { of people }\end{array}$ & $\begin{array}{l}\text { High and unexplained } \\
\text { variation in a very } \\
\text { short time span and } \\
\text { relevant effects likely } \\
\text { to be observed } \\
\text { between groups of } \\
\text { thousands of people }\end{array}$ & $\begin{array}{l}\text { Sample needs to be } \\
\text { extensively processed } \\
\text { or stored at }\left(80^{\circ} \mathrm{C}\right. \\
\text { or analysed fast } \\
\text { (e.g. in-line functional } \\
\text { assays) }\end{array}$ & $\begin{array}{l}\text { No commercially } \\
\text { available LDT } \\
\text { locally (in-house) } \\
\text { and validated/pub- } \\
\text { lished protocols } \\
\text { available }\end{array}$ & $\begin{array}{l}\text { Requires an expert } \\
\text { outside the laboratory, } \\
\text { medical surveillance } \\
\text { and/or specific equip- } \\
\text { ment (e.g. colono- } \\
\text { scopy, biopsies, } \\
\text { investigative flow } \\
\text { cytometry and chemi- } \\
\text { cal sensitisation) }\end{array}$ \\
\hline
\end{tabular}

CRP, C-reactive protein; IVD, in vitro diagnostics; CE Mark, a mandatory conformity mark for products placed on the market in the European Economic Area; FDA, US Food and Drug Administration; PBMC, peripheral blood mononuclear cells; LDT, laboratory-developed tests; CLIA, Clinical Laboratory Improvement Amendments; RUO, research use only. 


\section{Selection and prioritisation of markers}

Over seventy-five commonly used or recommended markers were evaluated according to the criteria specified in Table 1. For these markers, Tables 2 and 3 indicate the following: (1) whether a marker has relevance for the general population or is mainly relevant for specific subpopulations; (2) scores given for each of the defined criteria detailed in Table 1, all scored from 0 to +++ ; (3) an overall marker score indicating the subjective expert judgement on the usefulness of each marker based on the weighed evaluation of scores for individual criteria ( $\square$, not very useful; $\mathbf{n}$, low suitability; $\mathbf{\square}$, medium suitability; and $\mathbf{m}$, high suitability); (4) practicalities associated with the assessment of a marker (need for expensive, specialised equipment, need for repeated assessments, etc.); (5) plausible link to the three domains of immune function (scored not relevant $(0)$ to most relevant $(+++)$ for each domain), including defence against pathogens, avoidance or mitigation of allergy, and control of low-grade metabolic inflammation; (6) references illustrating the use of a particular marker in nutrition studies.

Table 2 summarises the clinical symptoms and in vivo markers for the three domains of physiological immune function. Symptoms of conditions that are relatively common in the general population are sometimes used as indirect markers of immune function. Clearly, they provide the most clinically relevant indication of intervention effects, but it is important to realise that symptoms by themselves may not necessarily indicate altered immune function because other nonimmune system-mediated mechanisms may be responsible for the changes in symptom scores. As self-assessment has been criticised for being subjective, unspecific and therefore unreliable, it is important that symptoms be scored by qualified persons blinded to the intervention. Alternatively, properly validated questionnaires can be used, which may be complemented by confirmation of symptoms by qualified persons. Examples of validated questionnaires include the Jackson $^{(60-62)}$ and Wisconsin ${ }^{(63-65)}$ scores for respiratory infections, the Vesikari ${ }^{(66)}$ or $\mathrm{WHO}^{(67)}$ scores for diarrhoea, SCORing Atopic Dermatitis (SCORAD) ${ }^{(68-70)}$ for eczema, Allergic Rhinitis and its Impact on Asthma ${ }^{(71)}$ for rhinitis, Asthma Control Test ${ }^{(72)}$ or Test for Respiratory and Asthma Control in Kids ${ }^{(73)}$ for asthma, and Mini Nutrition Surveys for the health and well-being of elderly individuals ${ }^{(74,75)}$. Because symptoms of naturally occurring infections or allergies develop at unpredictable moments and relatively infrequently in the general population, they are only useful as markers in studies of sufficient size and duration. To some extent, this can be addressed by performing the study in periods with increased incidence (e.g. winter for respiratory infections and spring/summer for hay fever) or by selecting (sub)populations more prone to develop symptoms such as groups with a higher prevalence of getting infected (e.g. children in developing regions, elderly individuals in nursing homes, children attending day-care centres, shift workers, etc.) or populations predisposed to develop allergies (e.g. children of atopic parents). However, in such cases, it is important to evaluate to what extent the outcome of the study can still be extrapo- lated to the general population. Contrary to (common) infections and allergies, inflammatory responses do not lead to symptoms that can be usefully assessed in the general population. Low-grade metabolic inflammation associated with (visceral) adiposity or inflammation linked to ageing is quite common, but by itself does not lead to overt symptoms.

Instead of waiting for symptoms to occur due to natural causes, they can also be elicited as part of the study design using an experimental infection with (attenuated) pathogens or a provocation with allergens. For instance, studies have successfully assessed symptoms elicited by an experimental infection with rhinoviruses ${ }^{(76-78)}$, Shigella ${ }^{(79)}$, respiratory syncytial virus ${ }^{(80)}$ or enterotoxigenic Escherichia coli ${ }^{(81)}$. Likewise, acute symptoms elicited by ingestion ${ }^{(82,83)}$ or nasal application $^{(84,85)}$ of allergens such as those used for the diagnosis and monitoring of allergy can also be used as markers in nutrition studies, be it that they will only result in symptoms in subjects who are allergic to a particular allergen. Importantly, unlike naturally occurring symptoms in which the time of occurrence and the exact eliciting trigger are unknown, experimental challenges make it feasible to combine the assessment of symptoms with that of the markers of contributing immune function(s) and even the kinetics of responses can be monitored to help establish cause-effect relations.

Although it is scientifically very attractive to use experimental challenges leading to symptoms that can be associated with changes in specific immune functions, such an approach clearly has ethical constraints. In particular studies, it may be more feasible to use somewhat weaker or more localised challenges that do not lead to symptoms but still modulate the relevant immune functions. Such in vivo markers of immune function include responses to vaccination (as a model for the response to an infection), to dermal recall antigen application (as a model for immune surveillance of the skin), to (local) allergen challenge (as a model for allergic responsiveness) and to transient inflammatory responses triggered by a pro-inflammatory challenge (as a model for the resilience of inflammatory control).

Vaccines trigger in vivo immune responses almost without eliciting symptoms of disease that would result from inoculation with live virulent pathogens. Specific immune responses to vaccines that are part of a national vaccination schedule can be used as in vivo indicators of the integrated immune response to these vaccines. Alternatively, one or more selected vaccinations can be integrated into the design of a study. Selection or stratification of subjects based on pre-existing responsiveness and careful consideration of the vaccine used (e.g. oral $v$. injected, type and dose of adjuvant, primary $v$. booster, single $v$. multiple dose, and T-cell independent $v$. T-cell dependent) and time point(s) selected to assess the response (early exponential phase $v$. later plateau phase, $v$. detailed analysis of the kinetics of the response) in relation to the postulated mechanism of action and the population in which the study will be performed can help to increase the sensitivity to detect the modulation of responsiveness due to nutrition. Seroprotection is defined as an antibody titre superior to an established threshold for clinical protection specific to each vaccine ${ }^{(86,87)}$. Seroconversion is defined as a 
NS British Journal of Nutrition

Table 2. Clinical symptoms and in vivo immune function markers

\begin{tabular}{|c|c|c|c|c|c|c|c|c|c|c|c|c|c|c|c|}
\hline \multirow[b]{2}{*}{ Functions } & \multirow[b]{2}{*}{ Markers } & \multicolumn{4}{|c|}{ Clinical relevance ${ }^{*}$} & \multicolumn{2}{|c|}{ Biological sensitivity* } & \multicolumn{2}{|c|}{ Feasibility* } & \multirow[b]{2}{*}{$\begin{array}{l}\text { Arbitrary } \\
\text { marker } \\
\text { scoreł }\end{array}$} & \multirow[b]{2}{*}{ Practicality ${ }^{*}$} & \multicolumn{3}{|c|}{ Plausibly linked to } & \multirow[b]{2}{*}{$\begin{array}{l}\text { Example } \\
\text { references }\end{array}$} \\
\hline & & $\begin{array}{l}\text { Mainly } \\
\text { relevant for } \\
\text { specific } \\
\text { subpopulations }\end{array}$ & $\begin{array}{l}\text { Differentially } \\
\text { expressed }\end{array}$ & $\begin{array}{l}\text { Correlates } \\
\text { with } \\
\text { clinical } \\
\text { endpoint }\end{array}$ & $\begin{array}{l}\text { Linked to } \\
\text { causal } \\
\text { pathway }\end{array}$ & $\begin{array}{l}\text { Within- } \\
\text { subject } \\
\text { variation }\end{array}$ & $\begin{array}{l}\text { Between- } \\
\text { subject } \\
\text { variation }\end{array}$ & Technical & Robustness & & & Pathogens & Allergy & Inflammation & \\
\hline \multirow{5}{*}{$\begin{array}{l}\text { Defence against } \\
\text { natural infec- } \\
\text { tions§ }\end{array}$} & Incidence of symptoms & No & +++ & +++ & +++ & + & + & +++ & +++ & m & ++ & +++ & 0 & $++/ 0 \|$ & $120-132$ \\
\hline & Duration of symptoms & No & +++ & +++ & +++ & + & + & ++ & ++ & חו & ++ & +++ & 0 & $++/ 0 \|$ & \\
\hline & Severity of symptoms & No & +++ & +++ & +++ & + & + & +++ & +++ & חומ & ++ & +++ & 0 & $++10 \|$ & \\
\hline & Pathogen loadף & No & ++ & ++ & +++ & + & + & + & + & $m$ & + & +++ & 0 & 0 & \\
\hline & $\begin{array}{l}\text { Pathogen-specific } \\
\text { immune response }\end{array}$ & No & ++ & + & ++ & NA & + & 0 & 0 & - & 0 & +++ & 0 & $++/ 0 \|$ & \\
\hline \multirow{5}{*}{$\begin{array}{l}\text { Defence against } \\
\text { experimental } \\
\text { infection }^{\star \star}\end{array}$} & Incidence of symptoms & No & +++ & ++ & +++ & NA & + & + & +++ & $m$ & 0 & +++ & 0 & 0 & $80,81,133-135$ \\
\hline & Duration of symptoms & No & +++ & ++ & +++ & NA & + & + & ++ & חומ & 0 & +++ & 0 & 0 & \\
\hline & Severity of symptoms & No & ++ & ++ & +++ & NA & + & + & +++ & سח & 0 & +++ & 0 & 0 & \\
\hline & Pathogen load & No & +++ & +++ & +++ & NA & + & + & ++ & mII & + & +++ & 0 & 0 & \\
\hline & $\begin{array}{l}\text { Pathogen-specific } \\
\text { immune response }\end{array}$ & No & +++ & ++ & +++ & NA & + & + & + & m & ++ & +++ & 0 & 0 & \\
\hline \multirow{4}{*}{$\begin{array}{l}\text { Response to } \\
\text { vacci- } \\
\text { nationt† }\end{array}$} & Seroprotection & No & +++ & +++ & +++ & NA & + & + & +++ & m & ++ & +++ & 0 & 0 & $136-141$ \\
\hline & Seroconversion & No & +++ & +++ & +++ & NA & + & + & +++ & ח & ++ & +++ & 0 & 0 & \\
\hline & $\begin{array}{l}\text { Vaccine-specific } \\
\text { antibodies (concen- } \\
\text { tration and titre) }\end{array}$ & No & ++ & ++ & ++ & NA & + & + & +++ & ח & ++ & +++ & 0 & 0 & \\
\hline & $\begin{array}{l}\text { Vaccine-specific T-cell } \\
\text { responsiveness }\end{array}$ & No & ++ & + & ++ & NA & + & + & +++ & m & ++ & +++ & 0 & 0 & \\
\hline \multirow[t]{3}{*}{$\begin{array}{l}\text { Immunosurveil- } \\
\text { lance of the } \\
\text { skin }\end{array}$} & $\begin{array}{l}\text { DTH response to local } \\
\text { recall antigen } \\
\text { application }\end{array}$ & Yes (sensitised) & ++ & ++ & +++ & + & + & ++ & ++ & $\omega$ & ++ & +++ & ++ & ++ & $137,142-146$ \\
\hline & Experimental CHS & No & ++ & ++ & ++ & + & + & ++ & 0 & m & 0 & ++ & +++ & ++ & 90,91 \\
\hline & $\begin{array}{l}\text { Migration of } \\
\text { Langerhans cells }\end{array}$ & No & + & 0 & + & + & + & + & 0 & - & 0 & ++ & +++ & 0 & 92,147 \\
\hline \multirow{3}{*}{$\begin{array}{l}\text { GI barrier } \\
\quad \text { functionł‡ }\end{array}$} & Sugar permeability & No & + & ++ & + & + & + & ++ & 0 & - & ++ & +++ & + & +++ & $122,148-152$ \\
\hline & Bacterial translocation & No & + & ++ & + & + & + & + & 0 & - & 0 & +++ & ++ & +++ & $153-155$ \\
\hline & Serum endotoxins & No & + & ++ & + & + & + & ++ & + & - & + & +++ & + & +++ & 154,156 \\
\hline \multirow[t]{3}{*}{$\begin{array}{l}\text { Tolerance to } \\
\text { allergens }\end{array}$} & Incidence of symptoms & $\begin{array}{l}\text { Yes (allergic } \\
\text { subjects) }\end{array}$ & ++ & +++ & +++ & + & + & ++ & 0 & ח & ++ & 0 & +++ & + & $\begin{array}{l}\text { 68,69, } \\
\quad 71-73,98 \\
157-163\end{array}$ \\
\hline & Duration of symptoms & $\begin{array}{l}\text { Yes (allergic } \\
\text { subjects) }\end{array}$ & + & 0 & + & + & + & + & + & - & 0 & 0 & +++ & + & \\
\hline & $\begin{array}{l}\text { Severity of symptoms } \\
\text { (e.g. peak flow, } \\
\text { SCORAD, ARIA, } \\
\text { Asthma Control Test } \\
\text { (ACT) and TRACK) }\end{array}$ & $\begin{array}{l}\text { Yes (allergic } \\
\text { subjects) }\end{array}$ & +++ & +++ & +++ & + & + & +++ & + & ח & +++ & 0 & +++ & + & \\
\hline \multirow{4}{*}{$\begin{array}{l}\text { Response to an } \\
\text { allergen } \\
\text { challenge }\end{array}$} & Prick test & $\begin{array}{l}\text { Yes (allergic } \\
\text { subjects) }\end{array}$ & +++ & +++ & +++ & + & + & ++ & ++ & an & ++ & 0 & +++ & 0 & $164-167$ \\
\hline & $\begin{array}{l}\text { Contact hypersensitivi- } \\
\text { ty/patch test }\end{array}$ & $\begin{array}{l}\text { Yes (allergic } \\
\text { subjects) }\end{array}$ & +++ & +++ & +++ & + & + & ++ & ++ & man & + & + & +++ & + & $\begin{array}{l}157,166, \\
168-172\end{array}$ \\
\hline & $\begin{array}{r}\text { Respiratory (nasal) } \\
\text { provocation test }\end{array}$ & $\begin{array}{l}\text { Yes (allergic } \\
\text { subjects) }\end{array}$ & +++ & +++ & +++ & +++ & ++ & ++ & + & $m$ & ++ & 0 & +++ & 0 & 173,174 \\
\hline & $\begin{array}{l}\text { Labial/nasal//oral } \\
\text { provocation test }\end{array}$ & $\begin{array}{l}\text { Yes (allergic } \\
\text { subjects) }\end{array}$ & +++ & +++ & +++ & + & + & ++ & + & m & ++ & 0 & +++ & 0 & $82,83,175$ \\
\hline
\end{tabular}




\begin{tabular}{|c|c|c|c|c|c|c|c|c|c|c|c|c|c|c|c|}
\hline \multirow[b]{2}{*}{ Functions } & \multirow[b]{2}{*}{ Markers } & \multicolumn{4}{|c|}{ Clinical relevance ${ }^{*}$} & \multicolumn{2}{|c|}{ Biological sensitivity* } & \multicolumn{2}{|c|}{ Feasibility* } & \multirow[b]{2}{*}{$\begin{array}{c}\text { Arbitrary } \\
\text { marker } \\
\text { scoreł }\end{array}$} & \multirow[b]{2}{*}{ Practicality* } & \multicolumn{3}{|c|}{ Plausibly linked to† } & \multirow[b]{2}{*}{$\begin{array}{l}\text { Example } \\
\text { references }\end{array}$} \\
\hline & & $\begin{array}{l}\text { Mainly } \\
\text { relevant for } \\
\text { specific } \\
\text { subpopulations }\end{array}$ & $\begin{array}{l}\text { Differentially } \\
\text { expressed }\end{array}$ & $\begin{array}{l}\text { Correlates } \\
\text { with } \\
\text { clinical } \\
\text { endpoint }\end{array}$ & $\begin{array}{l}\text { Linked to } \\
\text { causal } \\
\text { pathway }\end{array}$ & $\begin{array}{l}\text { Within- } \\
\text { subject } \\
\text { variation }\end{array}$ & $\begin{array}{l}\text { Between- } \\
\text { subject } \\
\text { variation }\end{array}$ & Technical & Robustness & & & Pathogens & Allergy & Inflammation & \\
\hline \multirow{3}{*}{$\begin{array}{l}\text { Symptomatic } \\
\text { inflammation }\end{array}$} & Incidence of symptoms & Yes (patients) & $0(+) \S \S$ & $0(++) \S \S$ & $0(++) \S \S$ & + & + & ++ & ++ & $\square(\mathbf{m}) \S \S$ & ++ & + & + & + & $2,32,156$ \\
\hline & Duration of symptoms & Yes (patients) & $0(+) \S \S$ & $0(++) \S \S$ & $0(++) \S \S$ & + & + & ++ & ++ & $\square(\mathbf{m} \mathbf{m}) \S \S$ & ++ & + & + & + & \\
\hline & Severity of symptoms & Yes (patients) & $0(++) \S \S$ & $0(++) \S$ & $0(++) \S \S$ & + & + & ++ & ++ & $\square(\mathbf{m a n}) \S \S$ & ++ & + & + & + & \\
\hline $\begin{array}{l}\text { Response to } \\
\text { inflammatory } \\
\text { challenges\|\|I }\end{array}$ & $\begin{array}{l}\text { Kinetics and amplitude } \\
\text { of induced inflam- } \\
\text { matory response } \\
\text { (assessed as acute- } \\
\text { phase protein, } \\
\text { cytokine or gene } \\
\text { expression) }\end{array}$ & No & + & + & ++ & + & + & ++ & + & $\square(\mathbf{\square}) \pi \pi$ & ++ & + & + & +++ & $31,176-179$ \\
\hline
\end{tabular}

NA, not applicable (cannot be assessed repeatedly in the same subject due to the development of immunological memory); DTH, delayed-type hypersensitivity; CHS, contact hypersensitivity; GI, gastrointestinal; ARIA, Allergic Rhinitis and its Impact on Asthma; TRACK, Test for Respiratory and Asthma Control in Kids.

* See Table 1 for score interpretation.

++++ , Most relevant: ++ , next most relevant: + , somewhat relevant: 0 , not relevant

¥ Arbitrary marker score is based on subjective expert judgement on the usefulness of a marker based on weighed evaluation of individual criteria. $\square$, Not very useful; $\mathbf{\square}$, low suitability; $\square$, medium suitability; $\square \mathbf{\square}$, high suitability. $\S$ Response to natural acute infections of respiratory tract (e.g. influenza virus and rhinovirus) or gastrointestinal tract (e.g. Clostridium difficile, enterotoxigenic Escherichia coli (ETEC) and rotavirus) or to natural chronic infection (e.g. cytomegalovirus (CMV), Epstein-Barr virus or Helicobacter pylor).

++ Indicates natural chronic infections (e.g. CMV and Epstein-Barr virus); 0 indicates acute infections.

I Pathogen-specific immune response such as pathogen-specific antibody titre or seroconversion or pathogen-specific T-cell response. Note that as with most natural infections, it is difficult to identify the responsible pathogen

${ }^{* *}$ Response to experimental infection (e.g. experimental rhinovirus infection, experimental infection with attenuated ETEC or experimental infection with respiratory syncytial virus).

†† Response to injected (systemic) or oral (mucosal) vaccination.

¥¥Mainly relevant in Gl patient populations.

$\$$ First score for low-grade metabolic inflammation, given in parentheses for patients with inflammatory conditions.

Response to injected endotoxin, oral fat load, oral glucose load and exercise challenge and initial innate (inflammatory) response to vaccination. Still mainly experimental.

११ Responses to inflammatory challenges seem promising, but relevance remains to be largely established. 
Table 3. Ex vivo and basal immune function markers

\begin{tabular}{|c|c|c|c|c|c|c|c|c|c|c|c|c|c|c|c|}
\hline \multirow[b]{2}{*}{ Functions } & \multirow[b]{2}{*}{ Markers } & \multicolumn{4}{|c|}{ Clinical relevance ${ }^{\star}$} & \multicolumn{2}{|c|}{ Biological sensitivity* } & \multicolumn{2}{|c|}{ Feasibility* } & \multirow[b]{2}{*}{$\begin{array}{c}\text { Arbitrary } \\
\text { marker } \\
\text { scoref } \\
\end{array}$} & \multirow[b]{2}{*}{ Practicality* } & \multicolumn{3}{|c|}{ Plausibly linked to† } & \multirow[b]{2}{*}{ Example references } \\
\hline & & $\begin{array}{c}\text { Mainly relevant } \\
\text { for specific } \\
\text { subpopulations } \\
\end{array}$ & $\begin{array}{c}\text { Differentially } \\
\text { expressed }\end{array}$ & $\begin{array}{l}\text { Correlates } \\
\text { with } \\
\text { clinical } \\
\text { endpoint } \\
\end{array}$ & $\begin{array}{c}\text { Linked } \\
\text { to } \\
\text { causal } \\
\text { pathway } \\
\end{array}$ & $\begin{array}{l}\text { Within- } \\
\text { subject } \\
\text { variation }\end{array}$ & $\begin{array}{c}\text { Between- } \\
\text { subject } \\
\text { variation }\end{array}$ & Technical & Robustness & & & Infection & Allergy & Inflammation & \\
\hline \multicolumn{16}{|l|}{$\begin{array}{l}\text { Systemic immune function } \\
\text { markers }\end{array}$} \\
\hline $\begin{array}{l}\text { Ex vivo (integrated) } \\
\text { Immune risk profile } \\
\text { (specific to elderly } \\
\text { individuals) }\end{array}$ & $\begin{array}{l}\text { Predefined profile (e.g. } \\
\text { CD4:CD8 ratio, B-cell } \\
\text { count, proliferative } \\
\text { response, naive cell } \\
\text { counts, NK-cell activity } \\
\text { and phagocyte function) }\end{array}$ & Yes§ & ++ & ++ & + & + & + & + & + & m & + & +++ & 0 & ++ & $180-183$ \\
\hline \multirow{3}{*}{$\begin{array}{l}\text { Ex vivo innate } \\
\text { Phagocyte function }\end{array}$} & & & & & & & & & & & & & & & \\
\hline & Phagocytosis & No & ++ & ++ & ++ & + & + & + & + & m & + & +++ & 0 & 0 & $184-193$ \\
\hline & $\begin{array}{l}\text { Oxidative burst } \\
\text { Migration of cells }\end{array}$ & $\begin{array}{l}\text { No } \\
\text { No }\end{array}$ & $\stackrel{+}{0}$ & $\begin{array}{l}++ \\
++\end{array}$ & $\begin{array}{l}++ \\
++\end{array}$ & $\begin{array}{l}+ \\
+\end{array}$ & $\begin{array}{l}+ \\
+\end{array}$ & $\begin{array}{l}+ \\
+\end{array}$ & $\begin{array}{l}+ \\
+\end{array}$ & - & $\begin{array}{l}+ \\
+\end{array}$ & $\begin{array}{l}+++ \\
+++\end{array}$ & $\begin{array}{l}0 \\
0\end{array}$ & $\begin{array}{l}0 \\
+\end{array}$ & \\
\hline \multirow{2}{*}{ NK-cell function } & NK-cell activity\| & No & ++ & ++ & ++ & + & + & + & + & - & + & +++ & 0 & 0 & $15,194-202$ \\
\hline & LAK cell activity\| & No & ++ & ++ & ++ & + & + & + & + & - & + & +++ & 0 & 0 & \\
\hline \multirow[t]{2}{*}{ APC function } & $\begin{array}{l}\text { Expression of activation and } \\
\text { differentiation markers } \\
\text { (e.g. CD83, CD80, CD86, } \\
\text { CD40 and HLA-DR) }\end{array}$ & No & ++ & + & ++ & + & + & + & + & m & + & +++ & ++ & ++ & $15,203-210$ \\
\hline & Expression of TLR & No & ++ & + & ++ & + & ++ & 0 & + & m & + & +++ & ++ & ++ & \\
\hline \multirow[t]{2}{*}{$\begin{array}{l}\text { Bioactive mediator } \\
\text { production (by PBMC } \\
\text { or whole blood) }\end{array}$} & $\begin{array}{l}\text { Production of cytokines } \\
\text { (pro-/anti-inflammatory } \\
\text { profiles) }\end{array}$ & No & ++ & + & ++ & + & ++ & ++ & ++ & m & ++ & +++ & ++ & +++ & $127,211-218$ \\
\hline & Production of eicosanoids & No & 0 & + & + & + & + & + & 0 & - & + & +++ & +++ & +++ & \\
\hline \multirow{5}{*}{$\begin{array}{l}\text { Ex vivo adaptive } \\
\text { T-cell function\| }\end{array}$} & Proliferationף & No & ++ & +t & ++ & + & + & ++ & + & ח & ++ & +++ & ++ & ++ & $219-221$ \\
\hline & $\begin{array}{l}\text { Expression of activation mar- } \\
\text { kers (e.g. CD25, CD69, } \\
\text { CD95 and HLA-DR) }\end{array}$ & No & ++ & ++ & ++ & + & + & ++ & + & m & ++ & +++ & ++ & ++ & $127,143,144,203,222-224$ \\
\hline & $\begin{array}{l}\text { Production of cytokines } \\
\text { (e.g. Th1/Th2/Th17) }\end{array}$ & No & ++ & ++ & ++ & + & + & ++ & + & m & ++ & +++ & + & +++ & $225-230$ \\
\hline & Cytotoxicity & No & ++ & ++ & ++ & + & + & +t & + & m & + & +++ & + & ++ & 231,232 \\
\hline & $T_{\text {reg function }}$ & No & ++ & ++ & ++ & + & + & + & + & $\bar{\square}$ & ++ & +++ & + & +++ & $233-238$ \\
\hline \multirow[t]{2}{*}{ B-cell function\| } & $\begin{array}{l}\text { Production of Ig (polyclonal } \\
\text { or secific) }\end{array}$ & Noף & + & + & + & + & + & ++ & + & 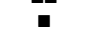 & ++ & ++ & ++ & + & 120,239 \\
\hline & Ig class switch & No & 0 & + & 0 & + & + & + & + & $\square$ & ++ & ++ & + & + & $123,127,240,241$ \\
\hline $\begin{array}{l}\text { Specific IgE } \\
\text { sensitisation }\end{array}$ & Basophil activation test & Yes (allergic) & +++ & +++ & ++ & + & + & ++ & + & ח & ++ & 0 & +++ & 0 & $111,112,115,222,242-244$ \\
\hline \multicolumn{16}{|l|}{$\begin{array}{l}\text { sensitisation } \\
\text { Basal markers (numbers } \\
\text { or concentrations in } \\
\text { blood or plasma) }\end{array}$} \\
\hline \multirow[t]{5}{*}{ Cells } & Differential cell counts & No & ++ & ++ & + & +t & ++ & +t & +++ & m & ++ & ++ & + & ++ & $181,243,245$ \\
\hline & $\begin{array}{l}\text { Basic lymphocyte subsets } \\
\text { (e.g. T, B, NK and } \\
\text { CD4:CD8 ratio) }\end{array}$ & No & + & + & + & ++ & ++ & ++ & ++ & - & ++ & +++ & + & ++ & $28,59,222$ \\
\hline & $\begin{array}{l}\text { Sophisticated subsets (e.g. } \\
\text { CDL5RARO, } \\
\text { Killer T-cells (NKT), } \\
\text { pDC and } \text { (NDC) }\end{array}$ & No & + & + & + & ++ & ++ & ++ & + & - & + & ++ & + & ++ & $28,127,222,246$ \\
\hline & $\begin{array}{l}\text { Expression of activation mar- } \\
\text { kers (e.g. CD25, CD69, } \\
\text { CD95 and HLA-DR) }\end{array}$ & No & + & + & + & + & ++ & ++ & ++ & - & ++ & +++ & + & ++ & 243,247 \\
\hline & $\begin{array}{l}\text { T- and B-cell repertoires } \\
\text { (clonality) }\end{array}$ & $\mathrm{No}^{* *}$ & + & + & + & + & + & + & + & 口 & ++ & +++ & ++ & ++ & $123,126,248,249$ \\
\hline \multirow[t]{5}{*}{ Mediators } & $\begin{array}{l}\text { Acute-phase proteins (e.g. } \\
\text { CRP and fibrinogen) }\end{array}$ & No & ++ & ++ & + & + & + & +++ & +++ & m & ++ & ++ & 0 & +++ & $116,250-253$ \\
\hline & Antigen-specific antibodies & No & ++ & + & ++ & ++ & ++ & ++ & + & m & ++ & ++ & ++ & + & 254 \\
\hline & Allergen-specific IgE & Yes (allergic) & ++ & ++ & ++ & ++ & ++ & ++ & ++ & $=$ & ++ & + & +++ & 0 & $114,255-261$ \\
\hline & $\begin{array}{l}\text { Ig isotypes (including } \\
\text { total IIE) }\end{array}$ & No & + & + & + & ++ & ++ & +++ & +++ & 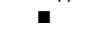 & ++ & ++ & ++ & + & 25,262 \\
\hline & Complement components & No & + & + & + & + & + & t++ & + & - & ++ & ++ & + & + & 263,264 \\
\hline
\end{tabular}




\section{N British Journal of Nutrition}

Table 3. Continued

\begin{tabular}{|c|c|c|c|c|c|c|c|c|c|c|c|c|c|c|c|}
\hline \multirow[b]{2}{*}{ Functions } & \multirow[b]{2}{*}{ Markers } & \multicolumn{4}{|c|}{ Clinical relevance ${ }^{\star}$} & \multicolumn{2}{|c|}{ Biological sensitivity* } & \multicolumn{2}{|c|}{ Feasibility* } & \multirow[b]{2}{*}{$\begin{array}{c}\text { Arbitrary } \\
\text { marker } \\
\text { scoref } \\
\end{array}$} & \multirow[b]{2}{*}{ Practicality* } & \multicolumn{3}{|c|}{ Plausibly linked to $†$} & \multirow[b]{2}{*}{ Example references } \\
\hline & & $\begin{array}{c}\text { Mainly relevant } \\
\text { for specific } \\
\text { subpopulations }\end{array}$ & $\begin{array}{c}\text { Differentially } \\
\text { expressed }\end{array}$ & $\begin{array}{l}\text { Correlates } \\
\text { with } \\
\text { clinical } \\
\text { endpoint } \\
\end{array}$ & $\begin{array}{c}\text { Linked } \\
\text { to } \\
\text { causal } \\
\text { pathway } \\
\end{array}$ & $\begin{array}{l}\text { Within- } \\
\text { subject } \\
\text { variation }\end{array}$ & $\begin{array}{c}\text { Between- } \\
\text { subject } \\
\text { variation }\end{array}$ & Technical & Robustness & & & Infection & Allergy & Inflammation & \\
\hline & $\begin{array}{l}\text { Cytokines, chemokines and } \\
\text { matrix metalloproteinases }\end{array}$ & No & + & + & + & + & + & ++ & + & - & ++ & +++ & ++ & +++ & $183,212,265,266$ \\
\hline & $\begin{array}{l}\text { Profiles of cytokines (e.g. } \\
\text { pro-/anti-inflammatory and }\end{array}$ & No & ++ & ++ & + & + & + & ++ & + & $m$ & ++ & +++ & ++ & +++ & $267-269$ \\
\hline & $\begin{array}{l}\text { Soluble receptors (e.g. } \\
\text { sCD14, sVCAM1 and } \\
\text { sICAM1) }\end{array}$ & No & + & + & + & + & + & ++ & + & - & ++ & + & 0 & +++ & $204,270,271$ \\
\hline & $\begin{array}{l}\text { Adipokines (e.g. adiponectin, } \\
\text { leptin and IGF) }\end{array}$ & No & ++ & + & + & + & + & ++ & + & - & + & + & 0 & +++ & $265,272-277$ \\
\hline & Serum calprotectin & No & + & + & + & + & ++ & ++ & + & $\square$ & ++ & + & 0 & + & 278,279 \\
\hline \multicolumn{16}{|l|}{$\begin{array}{l}\text { Local immune function } \\
\text { markers }\end{array}$} \\
\hline \multirow[t]{2}{*}{$\begin{array}{l}\text { Ex vivo markers } \\
\text { Local immune function }\end{array}$} & $\begin{array}{l}\text { Functional assays on biopsy } \\
\text { material (e.g. from the } \\
\text { intestine, adipose tissue } \\
\text { and skin) }\end{array}$ & Yes & ++ & ++ & ++ & + & + & 0 & + & m & 0 & ++ & 0 & +++ & $284-286$ \\
\hline & $\begin{array}{l}\text { Functional assays on nasal } \\
\text { or bronchoalveolar lavage }\end{array}$ & Yes & ++ & ++ & ++ & + & + & 0 & + & $m$ & 0 & ++ & +++ & 0 & $287-289$ \\
\hline \multicolumn{16}{|l|}{$\begin{array}{l}\text { Basal markers (numbers } \\
\text { and/or concentrations } \\
\text { in blood, plasma, saliva } \\
\text { and faeces) }\end{array}$} \\
\hline Cells & $\begin{array}{l}\text { Cellularity of biopsies or } \\
\text { lavage }\end{array}$ & Yes & ++ & ++ & ++ & + & + & 0 & + & $m$ & 0 & ++ & ++ & +++ & $287-289$ \\
\hline \multirow{3}{*}{ Soluble mediators } & $\begin{array}{l}\text { Homing markers on circulat- } \\
\text { ing cells }\end{array}$ & No & + & + & ++ & + & + & ++ & 0 & - & ++ & ++ & + & 0 & 285,290 \\
\hline & $\begin{array}{l}\text { Stool calprotectin } \\
\text { Secretory and stool Ig } \\
\text { (mucosal lgA) }\end{array}$ & $\begin{array}{l}\text { Noff } \\
\text { No }\end{array}$ & $\begin{array}{c}+ \\
++ \\
++\end{array}$ & $\begin{array}{c}++ \\
++\end{array}$ & $\begin{array}{c}+ \\
++\end{array}$ & $\begin{array}{l}+ \\
++\end{array}$ & $\begin{array}{l}+ \\
+\end{array}$ & $\begin{array}{l}+ \\
+\end{array}$ & $\begin{array}{c}+ \\
++\end{array}$ & man & $\begin{array}{c}+ \\
++\end{array}$ & $\begin{array}{l}+++ \\
+++\end{array}$ & $\begin{array}{l}0 \\
+\end{array}$ & $\begin{array}{l}+++ \\
+++\end{array}$ & $\begin{array}{l}291-293 \\
40,103,104,107,109, \\
\quad 294-296\end{array}$ \\
\hline & $\begin{array}{l}\text { Cytokine concentration, } \\
\text { e.g. in faecal } \\
\text { water/BAL/sputum }\end{array}$ & No & + & + & + & + & + & + & + & $\square$ & + & + & + & ++ & $297-304$ \\
\hline Mucus & $\begin{array}{l}\text { Amount of degradation of } \\
\text { mucus }\end{array}$ & Yes & + & + & + & + & + & ++ & + & $\square$ & + & +++ & ++ & +++ & $13,305-307$ \\
\hline
\end{tabular}

CD, cluster of differentiation; NK, natural killer; LAK, lymphokine-activated killer cells; APC, antigen-presenting cells; HLA, human leucocyte antigen; TLR, Toll-like receptor; PBMC, peripheral blood mononuclear cells; Th, T helper; $\mathrm{T}_{\text {reg, }}$, regulatory T cell; $\mathrm{pDC}$, plasmacytoid dendritic cells; $\mathrm{mDC}$, myeloid dendritic cell; CRP, C-reactive protein; sVCAM, soluble vascular cell adhesion molecule; sICAM, soluble intracellular adhesion molecule; IGF, insulin-like growth factor; BAL, bronchoalveolar lavage.

See Table 1 for score interpretation.

$\dagger+++$, Most relevant; ++ , next most relevant; + , somewhat relevant; 0 , not relevant.

† Arbitrary marker score is based on subjective expert judgement on the usefulness of a marker based on weighed evaluation of individual criteria. $\square$, Not very useful; $\mathbf{\square}$, low suitability; $\square \mathbf{m}$, medium suitability; $\square \mathbf{\square}$, high suitability. $\S$ Is associated with all-cause mortality in elderly individuals; relevance in other (sub)populations to be established.

Practical feasibility: 0 for $\mathrm{Cr},++$ for flow cytometry.

(a)

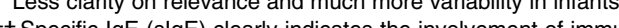

une function, but its relevance is controversial in the absence of concurrent clinical assessment. Some see it as a clinically relevant marker also used to guide therapy,

Food Safety Authority) emphasise that not all allergic subjects have slgE, not all subjects with slgE have allergic symptoms and changes in slgE are not always associated with changes in symptoms.

Mainly relevant in gastrointestinal patients. 
certain fold increase in specific antibody titres before and after vaccination ${ }^{(86)}$, e.g. at least a fourfold rise in the case of influenza vaccines ${ }^{(88)}$.

Delayed-type hypersensitivity (DTH) and contact hypersensitivity responses are local cell-mediated inflammatory responses triggered in sensitised individuals by the cutaneous administration of an antigen. Such responses can be measured $24-48 \mathrm{~h}$ after antigen application as epidermal induration ${ }^{(89)}$. For diagnostic purposes, DTH responses such as the prototypic Mantoux test have been largely replaced by more specific methods; however, as indicators of integrated in vivo cellular immune responsiveness, they remain valuable markers of immune function. However, standardised application has become complicated since the Cell Mediated Immunity (CMI) Multitest, in which seven different common antigenic preparations are administered simultaneously, is no longer available. Rigorously standardised application of antigenic material by syringe or prick is occasionally used; however, since application only yields DTH responses in sensitised subjects, it is important to apply a range of antigens. These problems have been overcome in several studies by experimentally sensitising subjects to uncommon chemical antigens not normally encountered. In this way, all subjects will respond, and the effect of nutrition on both the sensitisation and the elicitation phase of contact hypersensitivity responses can be assessed ${ }^{(90,91)}$. Although this is scientifically very attractive, there are clear ethical constraints. The same holds true for the assessment of Langerhans cells in skin biopsies, which can be used to assess temporal depletion of Langerhans cells due to migration induced by UV radiation. This is associated with increased susceptibility to (skin) infections, and mitigation of this depletion can, therefore, serve as a relevant marker of skin immune function ${ }^{(92)}$

The physical barrier of the gastrointestinal tract is central to the protection of the body against infections, allergens and inflammatory stimuli alike ${ }^{(93-96)}$. Tests designed to examine the integrity of the intestinal barrier typically involve the appearance of marker substances in plasma or urine after oral application of such substances (most often a nonmetabolised sugar) and/or of resident bacteria or components thereof such as endotoxins after translocation from the lumen of the intestine into the circulation. These markers are considered useful to assess alterations in intestinal barrier function, which is considered important in gastrointestinal infections and (food) allergies as well as low-grade inflammation. However, in the strict sense, such markers do not necessarily demonstrate alterations in (mucosal) immune function as the permeability may be altered by non-immunological mechanisms

In vivo provocation tests with allergens aim to reproduce allergic reactions in conditions as close as the natural exposure and using a lower dose and standardised conditions of exposure. Allergen provocation tests include intradermal injection or trans-cutaneous patches on the $\operatorname{skin}^{(97,98)}$, oral provocation with food allergens ${ }^{(99,100)}$ and mucosal (nasal, conjunctival, bronchial or labial) provocation with allergens ${ }^{(101,102)}$. While allergen provocation tests are quite safe to be used for most people, the possibility of anaphylaxis does exist and such tests should, therefore, only be done under clinical supervision.

Responsiveness to experimental inflammatory challenges has been suggested as a useful marker of inflammatory resilience. This involves the assessment of transient inflammatory responses induced by metabolic stressors (e.g. oral glucose or lipid load), infection stressors (e.g. injection with lipopolysaccharide, TNF, or IL-6 or the early response to the adjuvant components of vaccines) or tissue damage (e.g. acute exercise and exposure to UV radiation). Such dynamic responses to inflammatory challenges are promising markers of inflammatory resilience and are likely to be more relevant indicators of the ability to maintain inflammatory homeostasis than the mere static assessment of acute-phase proteins (e.g. CRP) or cytokines. However, there is a clear need for further standardisation of experimental protocols, and relevance in the general population remains to be established in prospective studies ${ }^{(31)}$.

The evaluation of a range of ex vivo and basal markers of immune function is summarised in Table 3. It is beyond the scope of this article to provide detailed technical information on the assessment of all of these immune function markers as they are quite commonly used and specific considerations have been discussed in a detailed manner elsewhere ${ }^{(1,18,22-25,27)}$. The references listed in the table provide pointers to specific details on the use of individual markers in nutrition studies.

\section{Clustering of markers according to clinical relevance and involvement of immune functions}

A selection of the most relevant markers given in Tables 2 and 3 are further categorised in Table 4 according to the most relevant functional domain (horizontally) while indicating (vertically) whether the markers by themselves are classified into the following groups. Group A is indicative of clinical relevance and involvement of immune function(s) (e.g. response to vaccination). Group B is indicative of clinical relevance but not necessarily of the involvement of immune function(s) (e.g. symptoms of diarrhoea). Group C is indicative of the involvement of immune function(s) and is associated with clinical relevance in specific (sub) populations (selected markers such as NK-cell activity, which is associated with infection risk in athletes and elderly individuals). Group D provides mechanistic insight into details of the immune function(s) involved, but not necessarily of clinical relevance (e.g. circulating levels of cytokines).

This classification helps in the interpretation of study outcomes and can also be used to further rationalise the selection of markers for inclusion in future studies. To some extent, it may also guide in making decisions in preclinical investigations. Clearly, markers of group A are most useful as they provide evidence for both clinical relevance and involvement of immune function(s) by themselves. However, it may not always be feasible to select markers from this group. In such cases, combining the assessment of markers from group $\mathrm{B}$ with that of markers from group $\mathrm{C}$ or $\mathrm{D}$ will lead to more confidence in the future interpretation of the data regarding clinical relevance and involvement of altered immune function(s). The same argument 
applies for a combination of group A markers with group C or D markers, linking clinical relevance with mechanistic insight. Such approaches will also result in new datasets that may be used to establish correlations of particular group C or D markers with clinical endpoints, which may lead to their evolution into group A markers within a reasonable time frame. In contrast, measuring numerous group B markers alone will lead to results that may be very clear regarding the clinical relevance, but remain inconclusive on the involvement of (altered) immune functions. Likewise, studies that focus exclusively on group D markers may very convincingly demonstrate that particular immune functions are altered, but the clinical relevance of these changes will remain largely elusive.

The list of markers given in Table 4 is non-exhaustive and should not be regarded as final since markers may evolve if more data become available. Instead, Table 4 provides the next step in a rational approach towards the design and interpretation of studies that aim to establish effects on immune function in the general population. The markers mentioned serve to illustrate how changes in these markers due to exogenous factors such as nutrition could be interpreted in the context of different scenarios described below. Selection and classification of the markers are based on the authors' expert judgement aided by discussion of an earlier version of this table with a wider group of experts.

It is noteworthy that many of the valuable group A markers indicating both clinical relevance and involvement of the immune system are 'challenge tests' comprising the assessment of in vivo responses of the immune system to a relevant (experimental) challenge. For defence against pathogens, these include immune responses to an (experimental) infection, to a vaccination and to a challenge with a recall antigen using a DTH or contact hypersensitivity test. For avoidance or mitigation of allergy, commonly used allergen provocation tests such as prick, intradermal and patch tests and labial, respiratory and oral challenges with specific allergens fall into this category. The corresponding pro-inflammatory challenge tests hold great promise as markers of the resilience of inflammatory control, but their clinical relevance has not been established yet ${ }^{(31)}$. For the time being, pro-inflammatory challenge tests are, therefore, classified as group $\mathrm{C}$ markers. In addition to the challenge tests, several other markers are placed in group A because they are clear indicators of the involvement of the immune system and their clinical relevance in the general population has been established, and modulation in the relevant direction would, therefore, be considered a beneficial health effect. For instance, mucosal IgA is a group A marker for defence against pathogens because it is a marker of immune function and low (salivary) IgA is a risk factor for respiratory infections in children and athletes $^{(103-110)}$. For avoidance or mitigation of allergy, the basophil activation test ${ }^{(111,112)}$ and tryptase ${ }^{(113)}$ in plasma are considered group A markers because they reflect basophil reactivity in allergic patients and are considered risk factors correlated with the severity of the reaction. Allergen-specific $\operatorname{IgE}$ (sIgE) clearly indicates the involvement of immune function; however, in the absence of concurrent clinical assessment, its relevance in the general population is controversial.
Some consider it as a clinically relevant marker (risk factor), whereas others (including the European Food Safety Authority) emphasise that not all allergic subjects have sIgE, not all subjects with sIgE have allergic symptoms and changes in sIgE are not always associated with changes in symptoms ${ }^{(114,115)}$. To acknowledge this controversy, we have indicated sIgE in groups A and C.

Group B markers are clinically relevant markers or endpoints (symptoms) that indicate the relevance of an effect, but in isolation do not prove the involvement of altered immune function as the effects could also be mediated via other mechanisms. For defence against pathogens, these include pathogen load and symptoms of common respiratory tract or gastrointestinal infections. Likewise, for avoidance or mitigation of allergy, symptoms of allergic responses due to undefined natural exposure to allergens indicate clinical relevance, but lack the specificity to prove the involvement of the immune system. This is also true for in vivo challenges with whole food products (milk) or substances such as lactose to which subjects may also respond with non-immune systemmediated intolerance. Low-grade inflammation does not lead to overt symptoms in the general population but is associated with reduced sensitivity to insulin and increased systolic blood pressure. However, these symptoms are not specific to lowgrade inflammation and can also be modified by other nonimmune system-mediated processes.

Group C markers typically reflect critical immune functions involved in the pathophysiological pathways underlying clinically relevant symptoms. Unlike group A markers, these markers are not generally accepted as markers of clinical relevance by themselves (risk factors), but there is ample evidence from relevant subpopulations that (alterations in) these markers are associated with (alterations in) clinical outcomes, and this is supported by a plausible mechanism of action. For instance, the precise predictive value of ex vivo NK-cell, phagocyte, or (pathogen-specific) T- or B-cell functions for infection risk is unknown. However, these immune functions are plausibly involved in the defence against pathogens, and a range of studies in elderly individuals, athletes, shift workers and other subpopulations have demonstrated that these ex vivo functional markers are inversely associated with the occurrence of symptomatic infections. Likewise, depletion of Langerhans cells in the skin due to UV radiation has been shown to be associated with an increased risk of (skin) infections, which plausibly is related to the reduced ability to present antigens and thus mount a protective immune response. For avoidance or mitigation of allergy, some feel that $\mathrm{sIgE}$ falls into this category for reasons discussed above. In addition, the remainder of ex vivo allergen-specific Th1and Th2-cell function, $\mathrm{T}_{\text {reg }}$ function and antigen-presenting cell function fall into this category. For the time being, in vivo responses to a pro-inflammatory challenge are a group C marker for inflammation control, but they may evolve to a group A marker if relevance can be established in prospective cohorts in the general population. Serum markers of the acute-phase response (such as CRP) or (ratios of) pro- and anti-inflammatory mediators do define low-grade asymptomatic inflammation, but are not accepted as proof of clinical 
Table 4. Clustering of selected markers according to clinical relevance and involvement of immune function(s)

\begin{tabular}{|c|c|c|c|c|}
\hline \multirow[b]{2}{*}{ Classification } & & \multicolumn{3}{|c|}{ Markers of immune function linked to } \\
\hline & & Defence against pathogens & $\begin{array}{l}\text { Avoidance or mitigation of hypersensitivity } \\
\text { (e.g. allergy) }\end{array}$ & $\begin{array}{l}\text { Inflammation control (reduction } \\
\text { of low-grade metabolic } \\
\text { inflammation) }\end{array}$ \\
\hline \multirow[t]{4}{*}{$\begin{array}{l}\text { Group } A \\
\text { marker }\end{array}$} & $\begin{array}{l}\text { Indicative of clinical relevance and involve- } \\
\text { ment of immune function(s) }\end{array}$ & $\begin{array}{l}\text { Pathogen-specific immune response (specific } \\
\text { antibodies and specific T-cell response } \\
\text { after natural or experimental infection) }\end{array}$ & $\begin{array}{l}\text { Specific response or symptoms after an } \\
\text { experimental allergen challenge (skin, } \\
\text { labial, respiratory or oral provocation tests) }\end{array}$ & NA \\
\hline & & $\begin{array}{l}\text { Vaccine-specific immune response (seropro- } \\
\text { tection, seroconversion, specific antibodies } \\
\text { and specific } T \text { cells) }\end{array}$ & Basophil activation test & \\
\hline & & Specific DTH or CHS response & Tryptase in plasma & \\
\hline & & Mucosal IgA (in saliva, tears, etc.) & Allergen-specific $\lg E(s \lg E)^{\star}$ & \\
\hline \multirow[t]{2}{*}{$\begin{array}{l}\text { Group B } \\
\text { marker }\end{array}$} & $\begin{array}{l}\text { Indicative of clinical relevance but not } \\
\text { necessarily of the involvement of immune } \\
\text { function(s) (i.e. clinical symptom) }\end{array}$ & $\begin{array}{l}\text { Symptoms of infection (incidence, duration } \\
\text { and severity after natural or experimental } \\
\text { infection) }\end{array}$ & $\begin{array}{l}\text { Symptoms of allergy (rhinitis, asthma, urti- } \\
\text { caria, eczema, GI manifestations, etc.) }\end{array}$ & $\begin{array}{l}\text { Symptoms associated with low- } \\
\text { grade inflammation (e.g. insulin } \\
\text { resistance and blood pressure) }\end{array}$ \\
\hline & & Pathogen load & Response to general food provocation & \\
\hline \multirow[t]{4}{*}{$\begin{array}{l}\text { Group C } \\
\text { marker }\end{array}$} & $\begin{array}{l}\text { Indicative of the involvement of immune } \\
\text { function(s) and associated with clinical } \\
\text { relevance in specific (sub)populations }\end{array}$ & Ex vivo (pathogen-specific) B-cell function & Allergen-specific IgE (slgE) ${ }^{\star}$ & $\begin{array}{l}\text { In vivo response to a pro-inflamma- } \\
\text { tory challenge }\end{array}$ \\
\hline & & Ex vivo (pathogen-specific) T-cell function & $\begin{array}{l}\text { Ex vivo (allergen-specific) Th1/Th2-cell } \\
\text { function }\end{array}$ & $\begin{array}{l}\text { Markers of acute-phase response } \\
\text { (CRP, TNF, IL-1, IL-6 and blood } \\
\text { sedimentation) }\end{array}$ \\
\hline & & Ex vivo phagocyte function & $\begin{array}{l}\text { Ex vivo (allergen-induced) production of } \\
\text { Th1/Th2 mediators }\end{array}$ & $\begin{array}{l}\text { (Ratio of) pro- and anti-inflamma- } \\
\text { tory mediators }\end{array}$ \\
\hline & & $\begin{array}{l}\text { Ex vivo NK-cell function } \\
\text { Migration of Langerhans cells }\end{array}$ & $\begin{array}{l}\text { Ex vivo } \mathrm{T}_{\text {reg }} \text {-cell function } \\
\text { Ex vivo APC function }\end{array}$ & $\begin{array}{l}\text { Ex vivo Th1/Th17/T } \mathrm{reg}^{\text {-cell function }} \\
\text { Ex vivo oxidative burst }\end{array}$ \\
\hline \multirow[t]{5}{*}{$\begin{array}{l}\text { Group D } \\
\text { marker }\end{array}$} & $\begin{array}{l}\text { Provides mechanistic insights but not } \\
\text { necessarily into clinical relevance } \\
\text { (non-exhaustive list of examples) }\end{array}$ & $\begin{array}{l}\text { Markers of acute-phase response (CRP, } \\
\text { TNF, IL-1, IL-6 and blood sedimentation) }\end{array}$ & $\begin{array}{l}\text { Markers of acute-phase response (CRP, } \\
\text { TNF, IL-1, IL-6 and blood sedimentation) }\end{array}$ & Plasma adiponectin and leptin \\
\hline & & $\begin{array}{l}\text { (Ratio of) pro- and anti-inflammatory } \\
\text { mediators }\end{array}$ & $\begin{array}{l}\text { (Ratio of) pro- and anti-inflammatory } \\
\text { mediators }\end{array}$ & Plasma endotoxin (LPS) \\
\hline & & $\begin{array}{l}\text { Percentage of subsets including CD4:CD8 } \\
\text { ratio }\end{array}$ & Total IgE & Plasma and faecal calprotectin \\
\hline & & $\begin{array}{l}\text { Circulating or ex vivo-produced antibodies } \\
\text { (not antigen- or vaccine-specific) }\end{array}$ & Circulating cytokines & \\
\hline & & Circulating or ex vivo-produced cytokines & Plasma and faecal calprotectin & \\
\hline
\end{tabular}


relevance in the general population. Nonetheless, there is a wealth of emerging data in various subpopulations including elderly individuals and obese and insulin-insensitive subjects, demonstrating that (alterations in) levels of these markers are associated with an increased risk of cardiovascular events and diabetes ${ }^{(116-119)}$. To a lesser extent, the same holds true for ex vivo oxidative burst and functionality of Th1, Th17 and $\mathrm{T}_{\text {reg }}$ subsets, all of which are, therefore, also considered group $\mathrm{C}$ markers.

Group D markers also indicate the involvement of particular immune functions, but contrary to group C markers, their critical involvement in the pathophysiology is less established and there is no convincing evidence (yet) that changes in these markers are associated with changes in relevant clinical outcomes. This has implications for the ability to interpret changes observed in these markers, as will be discussed below. In essence, group D contains 'all other' markers of immune function. The examples mentioned in Table 4 serve to contrast the categorisation of the same marker for different functional domains, such as markers of acute-phase response and (ratio of) pro- and anti-inflammatory markers as group $\mathrm{C}$ markers for inflammation control $v$ group $\mathrm{D}$ markers for defence against infection and avoidance or mitigation of allergy. Other examples contrast different markers within one functional domain, such as SIgE (group A or C) $v$. total IgE (group D) for avoidance of allergy or plasma adiponectin and leptin (group D) $v$. (ratio of) pro- and anti-inflammatory mediators (group C) for inflammation control.

It is important to note that for control of low-grade asymptomatic inflammation, there are no specific markers indicating clinical relevance (group A or B). Insulin resistance and blood pressure are very unspecific, and the clinical relevance of the most useful markers in this domain including response to inflammatory challenge, CRP and inflammatory mediators remains to be established in the general population. This lack of markers to establish clinical relevance severely hampers proper interpretation of effects on markers of low-grade inflammation. It is, therefore, of critical importance for progress in this area to establish the clinical relevance of the most promising markers using prospective cohorts in the general population. Such efforts should not only focus on concentrations or ratios of circulating inflammatory mediators, but also include responsiveness to rigorously standardised in vivo pro-inflammatory challenge tests as these types of challenge tests have been shown to be most useful in the other domains of immune function.

\section{Scenarios to interpret changes in (sets of) markers}

Following the definition of criteria, prioritisation of markers and classification according to conclusiveness for clinical relevance and involvement of immune function, we set out to devise a framework for the interpretation of changes observed in the different types of immune function markers, taking into account the type of marker and the changes observed relative to a defined reference range. Obviously, the proposed approach does not discount the need to critically consider the quality of individual studies and consistency of effects and to base the ultimate conclusions on the totality of evidence. Herein, we propose a theoretical framework to structure the interpretation of changes in immune function markers due to nutrition in the general population. As depicted and explained in more detail in Fig. 3, five scenarios were defined for changes in markers relative to the appropriate reference range.

The first step to interpret immune modulation in a particular setting is to determine whether one or more relevant markers of immune function are statistically significantly modulated by the intervention and, if so, to determine which of the scenarios applies. If the marker by itself indicates clinical relevance but not altered immune function (group B), and the effect is not accompanied by a plausibly linked change in a marker indicating altered immune function, then the effect is clinically relevant but may not necessarily be due to altered immune function and cannot be interpreted as such (e.g. reduced incidence or severity of diarrhoea on its own). If the marker by itself is indicative of immune function(s) and clinical relevance (group A marker), then the result can be interpreted as a beneficial modulation of immune function for scenarios 1, 2, 4 and 5. In scenario 3, this raises some concern and needs to be evaluated in more detail as described below. If the marker by itself is indicative of immune function(s), but in isolation does not indicate clinical relevance (group C), then interpretation as a beneficial modulation of immune function is possible for scenarios 1, 2, 4 and 5, if in the same or a similar study setting (a similar population or the same nutritional intervention), a marker indicating clinical relevance (group A or B) is also significantly changed and the changes are linked via a plausible mechanism. Again, for scenario 3, further evaluation is required to assess the potential for detrimental modulation of immune function, especially after prolonged exposure. For scenario 4, interpretation as a beneficial immune modulation would also be possible, but in this case, the intervention would prevent the negative changes occurring in the reference or control group. Finally, if the change is observed in a marker indicating altered immune function(s) but not necessarily clinical relevance in all populations (group C) and information on the markers of clinical relevance is lacking in the same or a similar study, then interpretation of the immune effects is not possible in scenario 1 , but may indicate a beneficial modulation in specific cases (scenarios 2, 4 and 5). This is depicted in Fig. 4. To explore this approach in more detail, it is applied to five scenarios discussed below with some examples for the different functional domains.

\section{Scenario 1: nutrition induces a significant modulation of a marker within the reference range}

If a relevant marker of immune function is statistically significantly modulated in the relevant direction and the marker per se is also indicative of the clinical relevance of effects observed (group A marker), such as improved responsiveness to an infection or a vaccine or reduced responsiveness to an (oral) allergen provocation test, then the modulation of this response within the reference range would be interpreted as a 


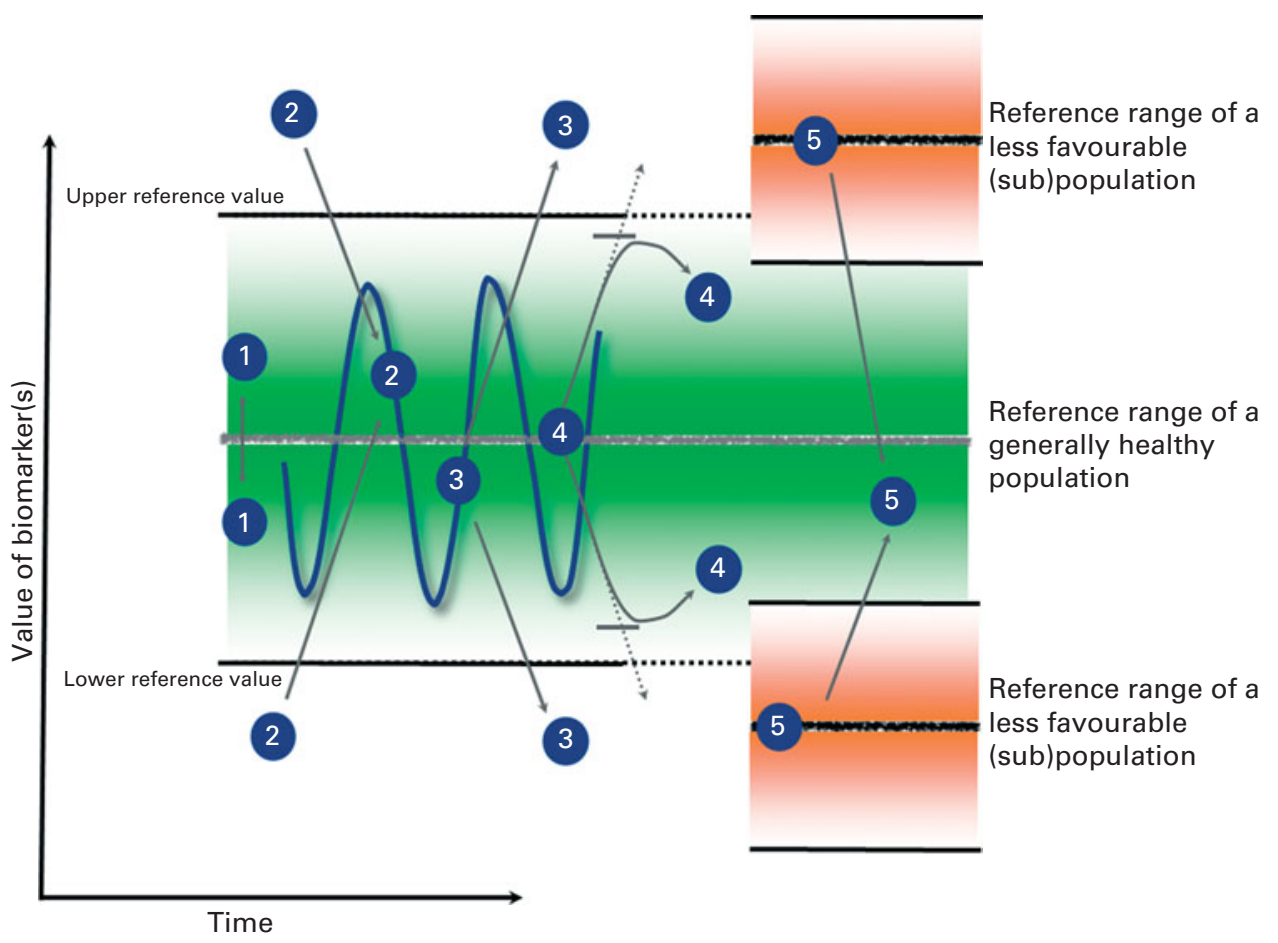

Fig. 3. Graphical representation of the five different scenarios for the modulation of immune function markers relative to the reference range. Scenario 1: statistically significant modulation within the reference range or within the range of a relevant control population, a very common scenario for modulation due to nutrition. Scenario 2: statistically significant modulation from outside the reference or control range of a relevant control population back into the range. Cases are different before intervention and become similar after intervention. Scenario 3: statistically significant modulation from within the reference or control range of a relevant control population out of the range. Cases are similar before intervention and become different after intervention. Scenario 4: nutritional prevention of statistically significant modulation induced by other endogenous or exogenous factors. Markers move out of the reference range of a relevant control population in the reference group, but this is prevented by nutrition in the intervention group (e.g. prevention of negative effects on the immune function of ageing or UV-B exposure or prevention of allergic sensitisation). Scenario 5: statistically significant modulation from a less favourable reference range to the reference range of a comparator group with a more desired immune function (e.g. from bottle-fed infants to breast-fed infants, elderly individuals to healthy adults, strenuous exercise to healthy controls, sleep deprivation to sleep sufficiency, etc.).

beneficial modulation of immune function within the specific domain. It is critical to consider the changes in immune functions within the context of a specific functional domain as for some markers the interpretation may differ depending on the domain. For instance, in the context of defence against pathogens, enhanced DTH to an antigenic challenge would be regarded as an enhanced response to a 'model infection' and would thus be considered beneficial. However, in the context of allergy, enhancement of a (delayed-type) hypersensitive response to an allergen challenge would be undesirable, whereas mitigation of such a response would be considered beneficial.

Similarly, if a statistically significant change in a marker indicative of immune function (group C) is plausibly linked to a statistically significant change in a marker of clinical relevance (group $\mathrm{B}$ marker), then the modulation of this marker could be interpreted as beneficial, and one can claim that nutrition improves immune defence against pathogens or helps to avoid or mitigate allergy or inflammation. For example, if consumption of a certain nutrient significantly reduced the duration of gastrointestinal infections during the winter season (group B) compared with a control group and concomitantly phagocyte function (group C) increased within the reference range in the infected subjects and these are plausibly linked based on mechanistic insights, the interpretation would be that this nutrient improves immune defence against pathogens. Another example in the field of allergy would be if consumption of a certain nutrient significantly reduced the severity of rhinitis (group B) compared with a control group and concomitantly Th2-cell function (group C) decreased within the reference range for the general population. In such cases, the interpretation would be that this nutrient mitigates hypersensitivity against allergens because these two markers are plausibly linked.

If the immune function marker belongs to the category of markers that are only indicative of the involvement of the immune system (group C or D) and evidence for concomitant changes in the markers of clinical relevance in the same or similar studies is lacking, then modulation within the reference range cannot be interpreted in terms of its health impact. However, complemented with other studies with acceptable biomarkers, such data could be used as supportive evidence of an immune regulatory effect. Finally, if the marker is indicative of clinical relevance but there is no significant change in plausibly associated markers of immune function (group B alone), clearly this is beneficial to health, but the effect may not necessarily be due to altered immune function and should not be interpreted as such. For instance, if the incidence or duration of diarrhoea is significantly reduced, this is beneficial. However, without additional information on 


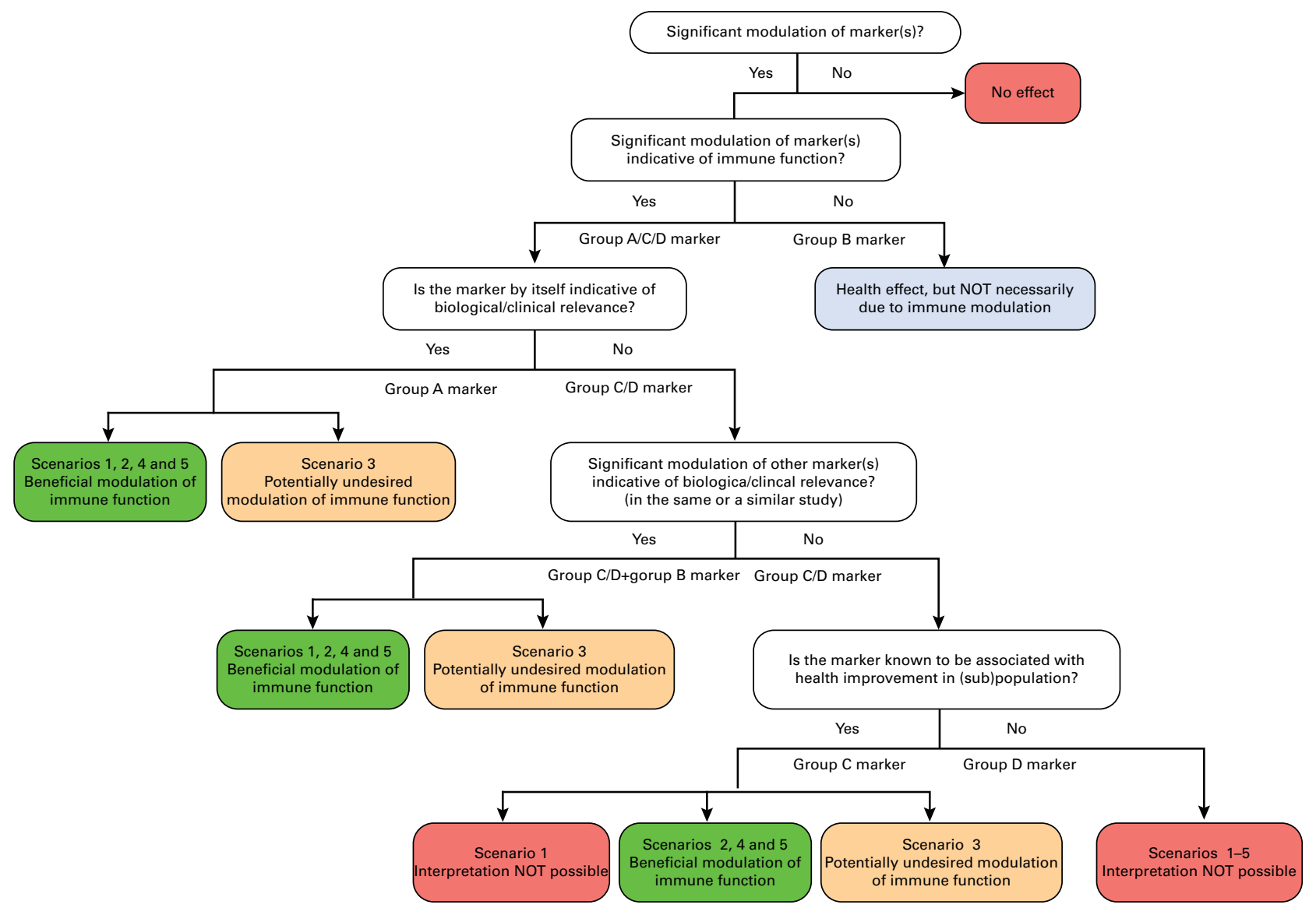

Fig. 4. Flow chart to aid the interpretation of changes in immune function markers in nutrition studies based on information on the type of markers in which significant changes are observed (groups $A-D$ ) and the relative change compared with the reference range (scenarios $1-5$ ). Blue indicates a health effect but not necessarily due to immune modulation, green indicates beneficial modulation of immune function, orange indicates potentially undesired modulation of immune function and red indicates no effect or interpretation not possible. Group A, relevance AND the involvement of immune functions (e.g. response to vaccination). Group B, relevance BUT NOT necessarily the involvement of immune functions (e.g. diarrhoea). Group C, involvement of immune function(s) AND associated with clinical relevance in specific (sub)populations (e.g. NK-cell activity in athletes and elderly). Group D, mechanistic insights BUT NOT directly associated with clinical relevance (e.g. cytokines).

changes in plausibly linked markers of immune function, this cannot be interpreted as a beneficial modulation of immune function because the underlying mechanism may be completely different.

Scenario 2: nutrition induces a significant modulation of a marker from outside the reference or control range back into the range

The interpretation for this scenario is essentially identical to that for scenario 1 with one addition. In the absence of data on changes in clinical relevance in the same or a similar study (the same intervention in a similar population), changes in markers indicative of immune function (group C) could potentially also be interpreted using a two-step argumentation if a change in these markers is described in the literature to be strongly associated with health improvement. An example may be if a (nutritional) intervention induced an increase in NK-cell activity back to the reference range and it is known that decreased levels of NK-cell activity have been strongly linked in the literature with decreased defence against patho- gens or tumours in particular populations (e.g. athletes and elderly individuals). If there is no such established association with clinically relevant outcomes in the literature, then the interpretation of the relevance of immune function marker modulation back to the reference range is not possible (group D). However, one could argue that modulation back into the reference range could be positively perceived in terms of reassurance against potential negative effects.

\section{Scenario 3: nutrition induces a significant modulation of a marker from within the reference or control range to outside the range}

If particular markers of immune function move from within the reference range to outside the reference range, such results should be interpreted within their context. In such situations, it may be useful to take the timing and sequence of events into account. For instance, if this occurs during an acute infection process, allergic manifestation or inflammatory episode, then the out-of-range markers may be more attributable to the ongoing host response to the infection/ 
allergens/inflammation rather than to the nutritional intervention. In such cases, it is also important to look at the magnitude of the effect and the consistency of changes observed among related markers. If it is not just a (statistical) artifact, but a consistent pattern of substantial modulation of related markers out of the reference range attributable to the intervention, then this is a sign to look more closely at potential unwanted side effects that could develop if this is sustained in the longer term.

Normally, such potentially deleterious effects should surface during animal studies in the preclinical phase. In the event that these emerge at a later stage, it would be recommended to initiate (additional) animal studies to gain a better mechanistic understanding and/or restrict use in humans to populations that are not at risk for the tentative adverse effects while initiating a 'pharmacovigilance'-type study (postmarketing surveillance study). Clearly, a careful consideration of the risks $v$. the benefits of longer-term exposure to such ingredients/products is warranted.

\section{Scenario 4: nutrition prevents a significant modulation of a marker from within the reference or control range to outside the range}

If particular markers of immune function in the control or reference group move from within the reference range to outside the range due to other factors and this is prevented by nutrition, this could be interpreted as a beneficial maintenance of normal immune function. In essence, this is the reverse of scenario 3 and would constitute increased resilience of the homeostatic regulatory mechanisms. This could involve the prevention of the negative impact of UV-B exposure or of strenuous exercise on immune function(s) or prevention or delay of ageing-associated immune senescence. Likewise, although allergen-sIgE is normally absent in a population, if followed prospectively, the levels of allergen-sIgE will increase in a subpopulation due to allergic sensitisation. Prevention of such negative effects could be interpreted as a beneficial modulation of immune function if the marker itself signifies clinical relevance as well as immune function (group A) or if evidence of plausibly linked markers of clinical relevance (group B) and contributing immune function (group C) can be combined. In the absence of data on clinical relevance in the same or similar studies, prevention of changes in markers indicative of immune function (group C) could potentially also be interpreted using a two-step argumentation if a change in these markers is described in the literature to be strongly associated with negative health effects. If there is no established association with clinically relevant outcomes, then the interpretation of the prevention of modulation of an immune function marker (group D) out of the reference range is less easy, although it could be positively perceived as an indication of increased resilience of homeostatic control. Finally, if the prevented modulation out of the reference range indicates clinical significance without evidence for the involvement of the immune system (group B by itself), the effect is beneficial for health, but may not necessarily be due to altered immune function.
Scenario 5: nutrition induces a significant modulation of a marker from a less favourable reference range into the reference range of a comparator group with a more favourable immune function

In this scenario, changes in markers are compared with the reference range of a population with a more favourable health profile. This reference range has been linked through a plausible mechanism to one or more immune functions. Typical examples would be to restore markers in elderly individuals to levels in healthy adults, in (overtrained) athletes back to normal ranges, and in more disease-prone shift workers to levels in less disease-prone controls with an undisturbed biorhythm; to move markers from atopic to normal ranges; or to shift markers of bottle-fed infants to normal ranges for breast-fed infants. Again, changes in markers indicative of clinical relevance or clearly established association with a plausible underlying mechanism are key to interpretation. In the case of immune function markers that also indicate clinical relevance (group A) or concomitant changes in plausibly linked group $\mathrm{B}$ and $\mathrm{C}$ markers, the interpretation is straightforward. For instance, if the responsiveness to vaccination in an elderly population shows increases to the range typically found for younger adults, this will be considered as beneficial. Likewise, reduction of elevated CRP levels in elderly individuals to ranges observed in healthy adults would be considered beneficial because lower levels of CRP have been associated with better survival.

\section{Beyond individual immune function markers}

In most nutrition intervention studies, (large) sets of immune function markers are assessed and the interpretation of intervention effects will depend on the consistency of the changes observed. If related immune function markers show consistent changes, the interpretation will be easy and will follow the same logic as for individual markers. For instance, if composite markers such as ratios of pro- and anti-inflammatory cytokines, ratios of distinct T-helper cell subset-related activation markers or cytokines, or a specified immune (risk) profile can be defined before the study, then reference ranges can be determined for these composite markers and nutritionrelated changes relative to these ranges can help guide the interpretation as described for individual markers above.

If changes in related markers are not consistent, interpretation is greatly helped by good clinical practices that include the a priori definition of the most important 'lead markers' (typically groups $\mathrm{A}$ and $\mathrm{B}$ ). The interpretation would be based on changes in these lead markers combined with mechanistic insights that may help to interpret the differential effects observed on the other markers. This could lead to the formulation of a new hypothesis that could then be tested in a new study specifically designed to test this hypothesis. Patterns or composite markers that are less well defined before the study, including those emerging from the untargeted use of high-content multiplexed or -omics approaches, are more difficult to interpret within this conceptual framework. However, such approaches could lead to the identification 
of pathways involved and can help to formulate specific hypotheses that can then be tested in more targeted followup studies.

It is thus advisable to define $a$ priori a cluster of the most important markers that are predictive of clinical effects or can be used as supportive evidence of clinical outcomes and that will aid in the eventual interpretation of the outcome of the intervention. These may be complemented with secondary parameters that present a profile that is indicative of a certain endpoint that may help in the interpretation of the mechanisms underlying potential changes in primary outcomes.

The same principles as described above for nutritional intervention studies may apply to other types of interventions and, with some caution, to observational studies exploring the relevance of (nutritional) differences between groups.

\section{Conclusions and recommendations}

The overall aim of this article is to provide further guidance for the assessment and interpretation of immune modulation by nutrition in the general population. To this end, criteria were defined to evaluate the strengths and weaknesses of symptoms and markers to measure changes in immune function. The markers were evaluated for three distinct domains of immune function: defence against pathogens; avoidance or mitigation of allergy; control of (low-grade) metabolic inflammation. Graded criteria were applied to over seventy-five immune function markers that were rated based on the different scores for their overall usefulness (Tables 2 and 3). Not surprisingly, it was found that markers that involve the standardised assessment of relevant symptoms (e.g. symptoms of common infections or allergies) or in vivo responses to a defined challenge with antigens or allergens (e.g. response to vaccination or allergen provocation) provide the most useful indication to interpret the modulation of immune function. Other useful markers include selected ex vivo markers of particular immune functions (e.g. NK-cell activity, phagocytosis and responsiveness of specific T-cell subpopulations) and selected basal markers essential in the exertion of critical immune functions, such as mucosal IgA for infection resistance, allergen-sIgE and tryptase for avoidance or mitigation of allergy, and CRP and inflammatory mediators to indicate low-grade inflammation.

A selection of the most useful markers were further classified depending on whether a change in the markers by itself conclusively indicates clinical relevance and/or involvement of altered immune function. Group A markers indicating both clinical relevance and involvement of immune function include pathogen- and vaccine-specific immune responses, DTH and contact hypersensitivity responses and mucosal IgA responses for defence against pathogens and for avoidance or mitigation of allergy-specific responses to allergen provocation, basophil activation and plasma tryptase. No group A markers were identified for control of low-grade metabolic inflammation. The classification of allergen-sIgE was controversial as some regard it to be a group A marker for allergy, whereas others are less convinced of its clinical relevance in the absence of symptoms in the general population.
Group B markers demonstrating clinical relevance, but not necessarily the involvement of immune function(s), include symptoms of infections and pathogen load for defence against pathogens as well as symptoms of allergy and response to general food or lactose provocation for allergy and insulin resistance and blood pressure as rather unspecific symptoms associated with low-grade metabolic inflammation. Several ex vivo cellular function assays associated with clinically relevant effects in (sub)groups of the general population and indicating the involvement of immune function(s) were clustered as group C. In addition, CRP and inflammatory markers were put into this category for their role in the control of lowgrade inflammation, and some argue that sIgE should also fit into this category for avoidance or mitigation of allergy. This group also comprises in vivo responses to pro-inflammatory challenges, which are considered promising markers for control of low-grade metabolic inflammation, but direct evidence for their clinical relevance remains to be established. Further optimisation, validation and inclusion of such challenge tests in prospective studies should be a high priority, as there are currently no other markers specifically indicating clinical relevance for the modulation of low-grade metabolic inflammation, hampering possibilities to design studies to demonstrate benefits of improved inflammatory control. Finally, group D contains all other immune function markers that can help to provide mechanistic insights, but for which the clinical relevance is currently unclear.

Clearly, there is no gold standard of immune function that can be recommended for all studies assessing the effects of nutrition on immune function in the general population. It is, therefore, proposed to first define the functional domain of interest and then select (combinations of) markers that indicate clinical relevance and for which a plausible hypothesis explaining how they could be related is available. For instance, to test the effect on resistance to pathogens, one could assess the response to a vaccination or combine the assessment of endpoints with specific responsiveness to an experimental infection. Alternatively, symptoms of natural infections could be assessed alongside with markers of immune function likely to be involved mechanistically. If the aim of the study is to test effects on mitigation of allergy, one could focus on provocation tests using specific allergens or combine the assessment of allergic symptoms with contributing group $\mathrm{C}$ or $\mathrm{D}$ markers. Finally, for control of low-grade metabolic inflammation, one could select a combination of markers including responsiveness to inflammatory challenge, CRP and pro- and anti-inflammatory mediators. However, it is important to realise that the clinical relevance of these markers remains to be established in the general population.

To aid the interpretation of changes observed in (combinations of) immune function markers, a framework was devised taking into account the type of marker and the changes observed relative to a defined reference range. Within this framework, five different scenarios were identified including (significant) modulation within the reference range (a very common scenario for modulation due to nutrition), modulation from outside the reference range back into the 
range, modulation from within the reference range out of the range, prevention of modulation induced by other factors, and modulation into the reference range of a comparator group with a more desired immune function (e.g. from values in bottle-fed infants to those in breast-fed infants). Evidently, this framework does not neglect the need to consider the quality of individual studies and consistency of effects and to consider that ultimate conclusions must be based on the totality of evidence. However, working through the logical steps of the proposed framework as presented in Fig. 4 indicates that selected (combinations of) markers can be used to reach clear conclusions as to whether an observed modulation of immune function could be regarded as beneficial within the functional domains of defence against pathogens and avoidance or mitigation of allergy. For control of low-grade metabolic inflammation, this is more difficult as there is a lack of specific markers linking altered immune function(s) to clinical relevance in this domain. Clearly, it is possible to reach conclusions on beneficial effects in situations of insulin resistance and high blood pressure. However, since these are only very loosely associated with low-grade inflammation, it will be challenging to firmly establish whether a concurrent modulation of (inflammatory) markers is correlated.

Finally, it is important to stipulate that the selection of markers and the complete approach are geared towards the assessment of effects on relevant physiological functions of the immune system or markers indicating benefits or risks at the group level within the general population. This is clearly distinct from the use of markers to diagnose or monitor the progression of disease in individual patients. Moreover, the evaluation and classification of markers indicated herein are based on an expert judgement of the authors, partially validated by discussions at a workshop with a wider group of experts. Scores and classification may be debated to some extent and conclusions for individual markers may change over time as more robust data on the association with relevant clinical outcomes in the general population become available. More importantly, the structured stepwise approach that was followed offers a rationale for selecting markers for future trials and helps to provide a framework for the interpretation of outcomes. In fact, a similar stepwise approach may also be useful to rationalise the selection and interpretation of markers for other physiological processes that are critical to the maintenance of health and well-being in the general population.

\section{Acknowledgements}

This work was conducted by an expert group of the European branch of the International Life Sciences Institute (ILSI Europe). The authors would like to thank Prof. Philippe Moreillon (University of Lausanne) who chaired this expert group in its early stages, as well as all participants of the workshop held on 16-17 April 2012 in Nice, France, for their active contribution to this work. This publication was coordinated by Marie Latulippe, Scientific Project Manager at ILSI Europe. The expert group received funding from the ILSI Europe Nutrition and Immunity and Probiotics Task Forces. Industry members of this task force are listed on the ILSI Europe website at www.ilsi.eu. For further information about ILSI Europe, email info@ilsieurope.be or call +32 277100 14. The opinions expressed herein and the conclusions of this publication are those of the authors and do not necessarily represent the views of ILSI Europe or those of its member companies.

Declaration of interest: R. A. was an employee of Unilever and is the founder of NutriLeads. R. B.-S. and I. L.-W. are employees of Danone. D. B. is an employee of Institut Merieux. P. C. C. received research funding from Beneo-Orafti, Beghin-Meiji, Abbott Nutrition and ViforPharma and is a consultant to Danone. U. H. is an employee of Mead Johnson Nutrition. A. M. is employed by ILSI Europe. A. O. is an employee of DuPont Nutrition and Health. P. P. is an employee of Nestlé. T. S. is an employee of Yakult Europe. A. S. is an employee of Friesland Campina. H. v. L. is a government employee and has no interests to declare. R. A., P. C. C., C. L., S. S., H. V. L. and U. S. received funding to attend meetings and a modest honoraria for their work on the manuscript. All authors contributed to the discussions and gave input for writing the article. All authors read and approved the final version of the article.

A draft of this report was discussed at a workshop held in Nice, France, from 16 to 17 May 2012. In addition to the authors, the following individuals attended the workshop and contributed to the discussions: Jean-Michel Antoine, Danone, France; Jalil Benyacoub, Nestlé Research Center, Switzerland; Per Brandtzaeg, Oslo University Hospital, Norway; Sylvie Chollet-Martin, Hôpital Bichat, France; Yvonne Dommels, Unilever R\&D, The Netherlands; John Flanagan, Naturex Spain S.L., Spain; Gert Folkerts, Utrecht University, The Netherlands; Claudio Franceschi, University of Bologna, Italy; Michael Gleeson, Loughborough University, UK; Thomas MacDonald, Centre for Immunology and Infectious Disease, UK; Giuseppe Matarese, Consiglio Nazionale delle Ricerche (IEOS-CNR), Italy; Annick Mercenier, Nestlé Research Center, Switzerland; Arjen Nauta, FrieslandCampina, The Netherlands; Ricardo Pujol-Borrell, Universitat Autònoma de Barcelona, Spain; Joseph Schwager, DSM Nutritional Products, Switzerland; Marie-Paule Vasson, Université d'Auvergne Clermont-Ferrand, France; Dominique Velin, University of Lausanne, Switzerland; Stéphane Vidry, ILSI Europe, Belgium; Renger Witkamp, Wageningen University, The Netherlands. The authors thank these individuals for their valuable input. This paper was published as a supplement to British Journal of Nutrition, publication of which was supported by ILSI Europe. The paper has undergone the standard journal formal review process and may be cited.

\section{References}

1. Albers R, Antoine JM, Bourdet-Sicard R, et al. (2005) Markers to measure immunomodulation in human nutrition intervention studies. Br J Nutr 94, 452-481.

2. Calder PC, Albers R, Antoine JM, et al. (2009) Inflammatory disease processes and interactions with nutrition. Br J Nutr 101, Suppl. 1, S1-S45.

3. Corthesy B, Gaskins HR \& Mercenier A (2007) Cross-talk between probiotic bacteria and the host immune system. J Nutr 137, 781S-790S. 
4. Esfahani A, Wong JMW, Truan J, et al. (2011) Health effects of mixed fruit and vegetable concentrates: a systematic review of the clinical interventions. J Am Coll Nutr 30, 285-294.

5. Florentino RF (2009) Symposium on diet, nutrition and immunity. Asia Pac J Clin Nutr 18, 137-142.

6. Forsythe P \& Bienenstock J (2010) Immunomodulation by commensal and probiotic bacteria. Immunol Invest 39, 429-448.

7. Gourbeyre P, Denery S \& Bodinier M (2011) Probiotics, prebiotics, and synbiotics: impact on the gut immune system and allergic reactions. J Leukoc Biol 89, 685-695.

8. Leavy O (2011) Mucosal immunology: the 'AHR diet' for mucosal homeostasis. Nat Rev Immunol 11, 806.

9. Lenoir-Wijnkoop I, Sanders ME, Cabana MD, et al. (2007) Probiotic and prebiotic influence beyond the intestinal tract. Nutr Rev 65, 469-489.

10. Lomax AR \& Calder PC (2009) Probiotics, immune function, infection and inflammation: a review of the evidence from studies conducted in humans. Curr Pharm Design 15, $1428-1518$.

11. Lomax AR \& Calder PC (2009) Prebiotics, immune function, infection and inflammation: a review of the evidence. Br J Nutr 101, 633-658.

12. Monk JM, Hou TY \& Chapkin RS (2011) Recent advances in the field of nutritional immunology. Expert Rev Clin Immunol 7, 747-749.

13. Rowland I, Capurso L, Collins K, et al. (2010) Current level of consensus on probiotic science - report of an expert meeting - London, 23 November 2009. Gut Microbes 1, 436-439.

14. Valdés-Ramos R, Martinez-Carrillo BE, Aranda-Gonzalez II, et al. (2010) Diet exercise and gut mucosal immunity. Proc Nutr Soc 69, 644-650.

15. van't Land B, Schijf MA, Martin R, et al. (2011) Influencing mucosal homeostasis and immune responsiveness: the impact of nutrition and pharmaceuticals. Eur J Pharmacol 668, Suppl. 1, S101-S107.

16. Veldhoen M \& Brucklacher-Waldert V (2012) Dietary influences on intestinal immunity. Nat Rev Immunol 12, 696-708.

17. Wallace TC, Guarner F, Madsen K, et al. (2011) Human gut microbiota and its relationship to health and disease. Nutr Rev 69, 392-403.

18. Walsh NP, Gleeson M, Shephard RJ, et al. (2011) Position statement. Part one: immune function and exercise. Exerc Immunol Rev 17, 6-63.

19. Walsh NP, Gleeson M, Pyne DB, et al. (2011) Position statement. Part two: maintaining immune health. Exerc Immunol Rev 17, 64-103.

20. Wichers H (2009) Immunomodulation by food: promising concept for mitigating allergic disease? Anal Bioanal Chem 395, 37-45.

21. Yan F \& Polk DB (2011) Probiotics and immune health. Curr Opin Gastroenterol 27, 496-501.

22. Afacan NJ, Fjell CD \& Hancock REW (2012) A systems biology approach to nutritional immunology - focus on innate immunity. Mol Aspects Med 33, 14-25.

23. Calder PC \& Kew S (2002) The immune system: a target for functional foods? Br J Nutr 88, Suppl. 2, S165-S177.

24. Calder PC (2007) Immunological parameters: what do they mean? J Nutr 137, 773S-780S.

25. Cummings JH, Antoine JM, Azpiroz F, et al. (2004) PASSCLAIM - gut health and immunity. Eur J Nutr 43, Suppl. 2, II118-II173.
26. Duramad P \& Holland NT (2011) Biomarkers of immunotoxicity for environmental and public health research. Int J Environ Res Public Health 8, 1388-1401.

27. Haller D, Antoine JM, Bengmark S, et al. (2010) Guidance for substantiating the evidence for beneficial effects of probiotics: probiotics in chronic inflammatory bowel disease and the functional disorder irritable bowel syndrome. $J$ Nutr 140, 690S-697S.

28. Maecker HT, McCoy JP Jr, Amos M, et al. (2010) A model for harmonizing flow cytometry in clinical trials. Nat Immunol 11, 975-978.

29. EFSA Panel on Dietetic Products Nutrition and Allergies (NDA) (2011) Guidance on the scientific requirements for health claims related to gut and immune function. EFSA J 9, 1984

30. Hamer M, Wolvers D \& Albers R (2004) Using stress models to evaluate immuno-modulating effects of nutritional intervention in healthy individuals. J Am Coll Nutr 23, 637-646.

31. Calder PC, Ahluwalia N, Albers R, et al. (2012) A consideration of biomarkers to be used for evaluation of inflammation in human nutritional studies. Br J Nutr 109, Suppl. 1, S1-S34.

32. Calder PC, Ahluwalia N, Brouns F, et al. (2011) Dietary factors and low-grade inflammation in relation to overweight and obesity. Br J Nutr 106, Suppl. 3, S5-S78.

33. vel Szic KS, Ndlovu MN, Haegeman G, et al. (2010) Nature or nurture: let food be your epigenetic medicine in chronic inflammatory disorders. Biochem Pharmacol 80, 1816-1832.

34. Gouin JP, Hantsoo L \& Kiecolt-Glaser JK (2008) Immune dysregulation and chronic stress among older adults: a review. Neuroimmunomodulation 15, 251-259.

35. Duramad P, Tager IB \& Holland NT (2007) Cytokines and other immunological biomarkers in children's environmental health studies. Toxicol Lett 172, 48-59.

36. Pae M, Meydani SN \& Wu D (2012) The role of nutrition in enhancing immunity in aging. Aging Dis 3, 91-129.

37. Darnall BD \& Suarez EC (2009) Sex and gender in psychoneuroimmunology research: past, present and future. Brain Behav Immun 23, 595-604.

38. Habbal OA \& Al-Jabri AA (2009) Circadian rhythm and the immune response: a review. Int Rev Immunol 28, 93-108.

39. Bollinger $\mathrm{T}$, Bollinger A, Oster $\mathrm{H}$, et al. (2010) Sleep, immunity, and circadian clocks: a mechanistic model. Gerontology 56, 574-580.

40. Cunniffe B, Griffiths H, Proctor W, et al. (2011) Mucosal immunity and illness incidence in elite rugby union players across a season. Med Sci Sports Exerc 43, 388-397.

41. Barriga-Ibars $\mathrm{C}$, Rodriguez-Moratinos $\mathrm{AB}$, Esteban $\mathrm{S}$, et al. (2005) [Interrelations between sleep and the immune status]. Rev Neurol 40, 548-556.

42. Brubaker AL, Palmer JL \& Kovacs EJ (2011) Age-related Dysregulation of Inflammation and Innate Immunity: Lessons Learned from Rodent Models. Aging Dis 2, 346-360.

43. Lau S, Gerhold K, Zimmermann K, et al. (2012) Oral application of bacterial lysate in infancy decreases the risk of atopic dermatitis in children with 1 atopic parent in a randomized, placebo-controlled trial. J Allergy Clin Immunol 129, 1040-1047.

44. Hojsak I, Snovak N, Abdovic S, et al. (2010) Lactobacillus GG in the prevention of gastrointestinal and respiratory tract infections in children who attend day care centers: a randomized, double-blind, placebo-controlled trial. Clin Nutr 29, 312-316.

45. Guillemard E, Tanguy J, Flavigny A, et al. (2010) Effects of consumption of a fermented dairy product containing the 
probiotic Lactobacillus casei DN-114 001 on common respiratory and gastrointestinal infections in shift workers in a randomized controlled trial. J Am Coll Nutr 29, 455-468.

46. Hoveyda N, Heneghan C, Mahtani KR, et al. (2009) A systematic review and meta-analysis: probiotics in the treatment of irritable bowel syndrome. BMC Gastroenterol 9, 15.

47. Sherman PM, Cabana M, Gibson GR, et al. (2009) Potential roles and clinical utility of prebiotics in newborns, infants, and children: proceedings from a global prebiotic summit meeting, New York City, June 27-28, 2008. J Pediatr 155 , S61-S70.

48. Usai-Satta P, Scarpa M, Oppia F, et al. (2012) Lactose malabsorption and intolerance: what should be the best clinical management? World J Gastrointest Pharmacol Ther 3, $29-33$.

49. van Meijl LE \& Mensink RP (2010) Effects of low-fat dairy consumption on markers of low-grade systemic inflammation and endothelial function in overweight and obese subjects: an intervention study. Br J Nutr 104, 1523-1527.

50. Graat JM, Schouten EG \& Kok FJ (2002) Effect of daily vitamin $\mathrm{E}$ and multivitamin-mineral supplementation on acute respiratory tract infections in elderly persons: a randomized controlled trial. JAMA 288, 715-721.

51. Ezzelle J, Rodriguez-Chavez IR, Darden JM, et al. (2008) Guidelines on good clinical laboratory practice: bridging operations between research and clinical research laboratories. J Pharm Biomed Anal 46, 18-29.

52. Francisco G, Hernandez C \& Simo R (2006) Serum markers of vascular inflammation in dyslipemia. Clin Chim Acta 369, $1-16$

53. National Institute of Allergy and Infectious Diseases (2009) Requirements for DAIDS Funded and/or Sponsored Laboratories in Clinical Trials. http://www.niaid.nih.gov/ LabsAndResources/resources/DAIDSClinRsrch/Documents/ laboratorypolicy1.pdf.

54. Stevens W (2003) Good clinical laboratory practice (GCLP): the need for a hybrid of good laboratory practice and good clinical practice guidelines/standards for medical testing laboratories conducting clinical trials in developing countries. Qual Assur 10, 83-89.

55. Stiles T \& Grant V (2011) Good Clinical Laboratory Practice (GCLP). Ipswich: BARQA.

56. Macey MG, McCarthy DA, Davies C, et al. (1997) The Q-Prep system: effects on the apparent expression of leucocyte cell surface antigens. Cytometry 30, 67-71.

57. Prabhakar U, Eirikis E, Reddy M, et al. (2004) Validation and comparative analysis of a multiplexed assay for the simultaneous quantitative measurement of Th1/Th2 cytokines in human serum and human peripheral blood mononuclear cell culture supernatants. J Immunol Methods 291, 27-38.

58. Sack U, Gerling F \& Tarnok A (2007) Age-related lymphocyte subset changes in the peripheral blood of healthy children - a meta-study. Transfus Med Hemother 34, 176-181.

59. Shearer WT, Rosenblatt HM, Gelman RS, et al. (2003) Pediatric AIDS Clinical Trials Group. Lymphocyte subsets in healthy children from birth through 18 years of age: the Pediatric AIDS Clinical Trials Group P1009 study. J Allergy Clin Immunol 112, 973-980.

60. Gwaltney JM Jr \& Hendley JO (2001) Respiratory transmission. In Epidemiologic Methods for the Study of Infectious Diseases [JC Thomas and DJ Weber, editors]. New York, NY: Oxford University Press.

61. Jackson GG, Dowling HF, Anderson TO, et al. (1960) Susceptibility and immunity to common upper respiratory viral infections - the common cold. Ann Intern Med $\mathbf{5 3}$ 719-738.
62. Jackson GG, Dowling HF \& Muldoon RL (1962) Acute respiratory diseases of viral etiology. VII. Present concepts of the common cold. Am J Public Health Nations Health 52, 940-945.

63. Barrett B, Brown R, Mundt M, et al. (2005) The Wisconsin Upper Respiratory Symptom Survey is responsive, reliable, and valid. J Clin Epidemiol 58, 609-617.

64. Barrett B (2006) Relations among questionnaire and laboratory measures of rhinovirus infection. Eur Respir $J \mathbf{2 8}$, 358-361.

65. Barrett B, Brown RL, Mundt MP, et al. (2009) Validation of a short form Wisconsin Upper Respiratory Symptom Survey (WURSS-21). Health Qual Life Outcomes 7, 76.

66. Ruuska T \& Vesikari T (1990) Rotavirus disease in Finnish children: use of numerical scores for clinical severity of diarrhoeal episodes. Scand J Infect Dis 22, 259-267.

67. World Health Organization (2005) The Treatment of Diarrhoea: A Manual for Physicians and Other Senior Health Workers. Geneva: WHO.

68. Gelmetti C \& Colonna C (2004) The value of SCORAD and beyond. Towards a standardized evaluation of severity? Allergy 59, Suppl. 78, 61-65.

69. Oranje AP (2011) Practical issues on interpretation of scoring atopic dermatitis: SCORAD index, objective SCORAD, patient-oriented SCORAD and three-item severity score. Curr Probl Dermatol 41, 149-155.

70. Oranje AP, Glazenburg EJ, Wolkerstorfer A, et al. (2007) Practical issues on interpretation of scoring atopic dermatitis: the SCORAD index, objective SCORAD and the threeitem severity score. Br J Dermatol 157, 645-648.

71. Jauregui I, Davila I, Sastre J, et al. (2011) Validation of ARIA (Allergic Rhinitis and its Impact on Asthma) classification in a pediatric population: the PEDRIAL study. Pediatr Allergy Immunol 22, 388-392.

72. Thomas M, Kay S, Pike J, et al. (2009) The Asthma Control Test (ACT) as a predictor of GINA guideline-defined asthma control: analysis of a multinational cross-sectional survey. Prim Care Respir J 18, 41-49.

73. Zeiger RS, Mellon M, Chipps B, et al. (2011) Test for Respiratory and Asthma Control in Kids (TRACK): clinically meaningful changes in score. J Allergy Clin Immunol 128, 983-988.

74. Bleda MJ, Bolibar I, Pares R, et al. (2002) Reliability of the mini nutritional assessment (MNA) in institutionalized elderly people. J Nutr Health Aging 6, 134-137.

75. Wikby K, Ek AC \& Christensson L (2008) The two-step Mini Nutritional Assessment procedure in community resident homes. J Clin Nurs 17, 1211-1218.

76. Turner RB, Riker DK \& Gangemi JD (2000) Ineffectiveness of echinacea for prevention of experimental rhinovirus colds. Antimicrob Agents Chemother 44, 1708-1709.

77. Turner RB \& Cetnarowski WE (2000) Effect of treatment with zinc gluconate or zinc acetate on experimental and natural colds. Clin Infect Dis 31, 1202-1208.

78. Broadbent DE, Broadbent MH, Phillpotts RJ, et al. (1984) Some further studies on the prediction of experimental colds in volunteers by psychological factors. $J$ Psychosom Res 28, 511-523.

79. Tacket CO, Binion SB, Bostwick E, et al. (1992) Efficacy of bovine milk immunoglobulin concentrate in preventing illness after Shigella flexneri challenge. Am J Trop Med Hyg 47, 276-283.

80. DeVincenzo JP, Wilkinson T, Vaishnaw A, et al. (2010) Viral load drives disease in humans experimentally infected with respiratory syncytial virus. Am J Resp Crit Care Med 182, 1305-1314. 
81. Bovee-Oudenhoven IMJ, Lettink-Wissink MLG, van Doesburg W, et al. (2003) Diarrhea caused by enterotoxigenic Escherichia coli infection of humans is inhibited by dietary calcium. Gastroenterology 125, 469-476.

82. Rolinck-Werninghaus C, Niggemann B, Grabenhenrich L, et al. (2012) Outcome of oral food challenges in children in relation to symptom-eliciting allergen dose and allergen-specific IgE. Allergy 67, 951-957.

83. Zomer-Kooijker K, Slieker MG, Kentie PA, et al. (2012) A prediction rule for food challenge outcome in children. Pediatr Allergy Immunol 23, 353-359.

84. Akerlund A, Andersson M, Leflein J, et al. (2005) Clinical trial design, nasal allergen challenge models, and considerations of relevance to pediatrics, nasal polyposis, and different classes of medication. J Allergy Clin Immunol 115, S460-S482.

85. Rondon C, Campo P, Herrera R, et al. (2011) Nasal allergen provocation test with multiple aeroallergens detects polysensitization in local allergic rhinitis. J Allergy Clin Immunol 128, 1192-1197.

86. European Medicines Agency (EMEA) (2006) Guideline on Clinical Evaluation of New Vaccines. London: EMEA.

87. Nauta JJ, Beyer WE \& Osterhaus AD (2009) On the relationship between mean antibody level, seroprotection and clinical protection from influenza. Biologicals 37, 216-221.

88. Committee for Proprietary Medicinal Products (1997) Note for Guidance on Harmonisation of Requirements for Influenza Vaccines. London: European Agency for the Evaluation of Medicinal Products.

89. Ananworanich J \& Shearer WT (2002) Delayed-type hypersensitivity skin testing. In Manual of Clinical Laboratory Immunology, pp. 212-219 [NR Rose, RG Hamilton and B Detrick, editors]. Washington, DC: ASM Press.

90. Harper Smith AD, Coakley SL, Ward MD, et al. (2011) Exercise-induced stress inhibits both the induction and elicitation phases of in vivo T-cell-mediated immune responses in humans. Brain Behav Immun 25, 1136-1142.

91. Sleijffers A, Garssen J, de Gruijl FR, et al. (2001) Influence of ultraviolet $\mathrm{B}$ exposure on immune responses following hepatitis B vaccination in human volunteers. I Invest Dermatol 117, 1144-1150.

92. Ruutu MP, Chen X, Joshi O, et al. (2011) Increasing mechanical stimulus induces migration of Langerhans cells and impairs the immune response to intracutaneously delivered antigen. Exp Dermatol 20, 534-536.

93. Marchiando AM, Graham WV \& Turner JR (2010) Epithelial barriers in homeostasis and disease. Annu Rev Pathol 5, 119-144.

94. Shimizu M (2010) Interaction between food substances and the intestinal epithelium. Biosci Biotechnol Biochem 74, $232-241$.

95. Turner JR (2009) Intestinal mucosal barrier function in health and disease. Nat Rev Immunol 9, 799-809.

96. Wershil BK \& Furuta GT (2008) 4. Gastrointestinal mucosal immunity. J Allergy Clin Immunol 121, S380-S383.

97. Darsow U \& Ring J (2000) Airborne and dietary allergens in atopic eczema: a comprehensive review of diagnostic tests. Clin Exp Dermatol 25, 544-551.

98. Bousquet J, Heinzerling L, Bachert C, et al. (2012) Practical guide to skin prick tests in allergy to aeroallergens. Allergy 67, 18-24.

99. Beyer K \& Teuber SS (2005) Food allergy diagnostics: scientific and unproven procedures. Curr Opin Allergy Clin Immunol 5, 261-266.

100. Niggemann B, Sielaff B, Beyer K, et al. (1999) Outcome of double-blind, placebo-controlled food challenge tests in
107 children with atopic dermatitis. Clin Exp Allergy 29 91-96.

101. Gosepath J, Amedee RG \& Mann WJ (2005) Nasal provocation testing as an international standard for evaluation of allergic and nonallergic rhinitis. Laryngoscope $\mathbf{1 1 5}$ $512-516$

102. Litvyakova LI \& Baraniuk JN (2001) Nasal provocation testing: a review. Ann Allergy Asthma Immunol 86, 355-364.

103. Fahlman MM \& Engels HJ (2005) Mucosal IgA and URTI in American college football players: a year longitudinal study. Med Sci Sports Exerc 37, 374-380.

104. Gleeson M, McDonald WA, Pyne DB, et al. (1999) Salivary IgA levels and infection risk in elite swimmers. Med Sci Sports Exerc 31, 67-73.

105. Gleeson M (2000) Mucosal immune responses and risk of respiratory illness in elite athletes. Exerc Immunol Rev 6, $5-42$.

106. Isaacs D, Webster AD \& Valman HB (1984) Immunoglobulin levels and function in pre-school children with recurrent respiratory infections. Clin Exp Immunol 58, 335-340.

107. Lehtonen OP, Tenovuo J, Aaltonen AS, et al. (1987) Immunoglobulins and innate factors of immunity in saliva of children prone to respiratory infections. Acta Pathol Microbiol Immunol Scand C 95, 35-40.

108. Mackinnon LT (1999) Advances in Exercise and Immunology. Champaign, IL: Human Kinetics.

109. Neville V, Gleeson M \& Folland JP (2008) Salivary IgA as a risk factor for upper respiratory infections in elite professional athletes. Med Sci Sports Exerc 40, 1228-1236.

110. van Riet E, Ainai A, Suzuki T, et al. (2012) Mucosal IgA responses in influenza virus infections; thoughts for vaccine design. Vaccine 30, 5893-5900.

111. Kosnik M, Silar M, Bajrovic N, et al. (2005) High sensitivity of basophils predicts side-effects in venom immunotherapy. Allergy 60, 1401-1406.

112. Lambert C, Guilloux L, Dzviga C, et al. (2003) Flow cytometry versus histamine release analysis of in vitro basophil degranulation in allergy to Hymenoptera venom. Cytometry B Clin Cytom 52, 13-19.

113. Rueff F, Przybilla B, Bilo MB, et al. (2009) Predictors of severe systemic anaphylactic reactions in patients with Hymenoptera venom allergy: importance of baseline serum tryptase - a study of the European Academy of Allergology and Clinical Immunology Interest Group on Insect Venom Hypersensitivity. J Allergy Clin Immunol 124, 1047-1054.

114. Holt PG, Rowe J, Kusel M, et al. (2010) Toward improved prediction of risk for atopy and asthma among preschoolers: a prospective cohort study. J Allergy Clin Immunol 125, 653-659, 659.e1-659.e7.

115. Ott H, Tenbrock K, Baron J, et al. (2011) Basophil activation test for the diagnosis of hymenoptera venom allergy in childhood: a pilot study. Klin Padiatr 223, 27-32.

116. Wensley F, Gao P, Burgess S, et al. (2011) Association between $\mathrm{C}$ reactive protein and coronary heart disease: mendelian randomisation analysis based on individual participant data. BMJ 342, d548.

117. Casas JP, Shah T, Hingorani AD, et al. (2008) C-reactive protein and coronary heart disease: a critical review. J Intern Med 264, 295-314.

118. Strandberg TE \& Tilvis RS (2000) C-reactive protein, cardiovascular risk factors, and mortality in a prospective study in the elderly. Arterioscler Thromb Vasc Biol 20, 1057-1060.

119. Clapp BR, Hirschfield GM, Storry C, et al. (2005) Inflammation and endothelial function: direct vascular effects of 
human C-reactive protein on nitric oxide bioavailability. Circulation 111, 1530-1536.

120. Dowd JB, Aiello AE, Chyu L, et al. (2011) Cytomegalovirus antibodies in dried blood spots: a minimally invasive method for assessing stress, immune function, and aging. Immun Ageing $\mathbf{8}, 3$.

121. Guarino A, Canani RB, Spagnuolo MI, et al. (1997) Oral bacterial therapy reduces the duration of symptoms and of viral excretion in children with mild diarrhea. J Pediatr Gastroenterol Nutr 25, 516.

122. Guarner F (2007) Studies with inulin-type fructans on intestinal infections, permeability, and inflammation. J Nutr $\mathbf{1 3 7}$, 2568S-2571S.

123. Lesourd BM (1997) Nutrition and immunity in the elderly: modification of immune responses with nutritional treatments. Am J Clin Nutr 66, 478S-484S

124. Mcfarland LV \& Elmer GW (2006) Meta-analysis of probiotics for the prevention and treatment of acute pediatric diarrhea. Int J Prebiotics Probiotics 1, 63-76.

125. Meydani SN (1993) Vitamin/mineral supplementation, the aging immune response, and risk of infection. Nutr Rev 51, 106-109.

126. Ngom PT, Solon J, Moore SE, et al. (2011) Thymic function and $\mathrm{T}$ cell parameters in a natural human experimental model of seasonal infectious diseases and nutritional burden. J Biomed Sci 18, 41.

127. Ongradi J \& Kovesdi V (2010) Factors that may impact on immunosenescence: an appraisal. Immun Ageing 7, 7.

128. Romeo J, Nova E, Warnberg J, et al. (2010) Immunomodulatory effect of fibres, probiotics and synbiotics in different life-stages. Nutr Hosp 25, 341-349.

129. Sazawal S, Hiremath G, Dhingra U, et al. (2006) Efficacy of probiotics in prevention of acute diarrhoea: a meta-analysis of masked, randomised, placebo-controlled trials. Lancet Infect Dis 6, 374-382.

130. Stowe RP, Kozlova EV, Yetman DL, et al. (2007) Chronic herpes virus reactivation occurs in aging. Exp Gerontol 42, 563-570.

131. Szajewska H, Skorka A, Ruszczyäski M, et al. (2007) Metaanalysis: Lactobacillus GG for treating acute diarrhoea in children. Aliment Pharmacol Ther 25, 871-881.

132. Vescovini R, Biasini C, Fagnoni FF, et al. (2007) Massive load of functional effector $\mathrm{CD}^{+}$and $\mathrm{CD}^{+} \mathrm{T}$ cells against cytomegalovirus in very old subjects. I Immunol 179, 4283-4291.

133. Peterson KM, O'Shea M, Stam W, et al. (2009) Effects of dietary supplementation with conjugated linoleic acid on experimental human rhinovirus infection and illness. Antivir Ther 14, 33-43.

134. Porter CK, Riddle MS, Tribble DR, et al. (2011) A systematic review of experimental infections with enterotoxigenic Escherichia coli (ETEC). Vaccine 29, 5869-5885.

135. Turner RB, Bauer R, Woelkart K, et al. (2005) An evaluation of Echinacea angustifolia in experimental rhinovirus infections. New Engl J Med 353, 341-348.

136. Hara M, Tanaka K \& Hirota Y (2005) Immune response to influenza vaccine in healthy adults and the elderly: association with nutritional status. Vaccine 23, 1457-1463.

137. Wolvers DA, van Herpen-Broekmans WM, Logman MH, et al. (2006) Effect of a mixture of micronutrients, but not of bovine colostrum concentrate, on immune function parameters in healthy volunteers: a randomized placebocontrolled study. Nutr J 5, 28.

138. Gupta K \& Cooper C (2008) A review of the role of CpG oligodeoxynucleotides as toll-like receptor 9 agonists in prophylactic and therapeutic vaccine development in infectious diseases. Drugs R D 9, 137-145.

139. Sangare L, Manhart L, Zehrung D, et al. (2009) Intradermal hepatitis B vaccination: a systematic review and metaanalysis. Vaccine 27, 1777-1786.

140. Gordon DL, Sajkov D, Woodman RJ, et al. (2012) Randomized clinical trial of immunogenicity and safety of a recombinant H1N1/2009 pandemic influenza vaccine containing Advax polysaccharide adjuvant. Vaccine 30, 5407-5416.

141. van Loveren $\mathrm{H}$, van Amsterdam JG, Vandebriel RJ, et al. (2001) Vaccine-induced antibody responses as parameters of the influence of endogenous and environmental factors. Environ Health Perspect 109, 757-764.

142. Dahlen I, Lindberg E, Janson C, et al. (1999) Delayed type of hypersensitivity and late allergic reactions in patients with stable COPD. Chest 116, 1625-1631.

143. Han SN, Leka LS, Lichtenstein AH, et al. (2003) Effect of a therapeutic lifestyle change diet on immune functions of moderately hypercholesterolemic humans. J Lipid Res $\mathbf{4 4}$, 2304-2310.

144. Hawkes WC, Hwang A \& Alkan Z (2009) The effect of selenium supplementation on DTH skin responses in healthy North American men. J Trace Elem Med Biol 23, 272-280.

145. Vukmanovic-Stejic M, Reed JR \& Lacy KE (2006) Mantoux Test as a model for a secondary immune response in humans. Immunol Lett 107, 93-101.

146. Wu D, Han SN, Meydani M, et al. (2006) Effect of concomitant consumption of fish oil and vitamin $\mathrm{E}$ on $\mathrm{T}$ cell mediated function in the elderly: a randomized doubleblind trial. J Am Coll Nutr 25, 300-306.

147. Nestle FO, Di MP, Qin JZ, et al. (2009) Skin immune sentinels in health and disease. Nat Rev Immunol 9, 679-691.

148. Arvola T, Moilanen E \& Vuento R (2004) Weaning to hypoallergenic formula improves gut barrier function in breast-fed infants with atopic eczema. J Pediatr Gastroenterol Nutr 38, 92-96.

149. Gotteland M, Andrews M, Toledo M, et al. (2008) Modulation of Helicobacter pylori colonization with cranberry juice and Lactobacillus johnsonii La1 in children. Nutrition 24, 421-426.

150. Westerbeek EA, Hensgens RL, Mihatsch WA, et al. (2011) The effect of neutral and acidic oligosaccharides on stool viscosity, stool frequency and stool $\mathrm{pH}$ in preterm infants. Acta Paediatr 100, 1426-1431.

151. Mullen A, Gosset L, Larke N, et al. (2012) The effects of micronutrient-fortified complementary/replacement food on intestinal permeability and systemic markers of inflammation among maternally HIV-exposed and unexposed Zambian infants. Br J Nutr 107, 893-902.

152. Willumsen JF, Darling JC, Kitundu JA, et al. (1997) Dietary management of acute diarrhoea in children: effect of fermented and amylase-digested weaning foods on intestinal permeability. J Pediatr Gastroenterol Nutr 24, 235.

153. Cole CR, Frem JC, Schmotzer B, et al. (2010) The rate of bloodstream infection is high in infants with short bowel syndrome: relationship with small bowel bacterial overgrowth, enteral feeding, and inflammatory and immune responses. J Pediatr 156, 941-7, 947.e1.

154. de Oliveira EP \& Burini RC (2011) Food-dependent, exercise-induced gastrointestinal distress. J Int Soc Sports Nutr $\mathbf{8}, 12$.

155. Maes M, Kubera M, Leunis JC, et al. (2012) Increased IgA and $\operatorname{IgM}$ responses against gut commensals in chronic depression: further evidence for increased bacterial translocation or leaky gut. J Affect Disord 141, 55-62. 
156. Andreasen AS, Larsen N, Pedersen-Skovsgaard T, et al. (2010) Effects of Lactobacillus acidophilus NCFM on insulin sensitivity and the systemic inflammatory response in human subjects. Br J Nutr 104, 1831-1838.

157. Baldassarre ME, Laforgia N \& Fanelli M (2010) Lactobacillus GG improves recovery in infants with blood in the stools and presumptive allergic colitis compared with extensively hydrolyzed formula alone. J Pediatr 156, 397-401.

158. Ji GE (2009) Probiotics in primary prevention of atopic dermatitis. Forum Nutr 61, 117-128.

159. Savilahti E, Kukkonen K \& Kuitunen M (2009) Probiotics in the treatment and prevention of allergy in children. World Allergy Organ J 2, 69-76.

160. Yoshimura M, Enomoto T, Dake Y, et al. (2007) An evaluation of the clinical efficacy of tomato extract for perennial allergic rhinitis. Allergol Int 56, 225-230.

161. Mlynek A, Zalewska-Janowska A, Martus P, et al. (2008) How to assess disease activity in patients with chronic urticaria? Allergy 63, 777-780.

162. Nermes M, Kantele JM, Atosuo TJ, et al. (2011) Interaction of orally administered Lactobacillus rhamnosus GG with skin and gut microbiota and humoral immunity in infants with atopic dermatitis. Clin Exp Allergy 41, 370-377.

163. McBride D, Keil T, Grabenhenrich L, et al. (2012) The EuroPrevall birth cohort study on food allergy: baseline characteristics of 12,000 newborns and their families from nine European countries. Pediatr Allergy Immunol 23, 230-239.

164. McLoughlin RM \& Mills KHG (2011) Influence of gastrointestinal commensal bacteria on the immune responses that mediate allergy and asthma. J Allergy Clin Immunol 127, 1097-1107.

165. Noverr MC \& Huffnagle GB (2004) Does the microbiota regulate immune responses outside the gut? Trends Microbiol 12, 562-568.

166. Spergel JM, Brown-Whitehorn TF, Beausoleil JL, et al. (2009) 14 years of eosinophilic esophagitis: clinical features and prognosis. J Pediatr Gastroenterol Nutr 48, 30-36.

167. Sucharew H, Khoury JC, Rao M, et al. (2011) Predicting allergic disease at age four using an atopy predisposition score at age two: the application of item response theory. Pediatr Allergy Immunol 23, 195-201.

168. Canani RB, Ruotolo S, Auricchio L, et al. (2007) Diagnostic accuracy of the atopy patch test in children with food allergy-related gastrointestinal symptoms. Allergy $\mathbf{6 2}$, $738-743$.

169. Canani RB, Buongiovanni A, Nocerino R, et al. (2011) Toward a standardized reading of the atopy patch test in children with suspected cow's milk allergy-related gastrointestinal symptoms. Allergy 66, 1499-1500.

170. Martin SF (2012) Contact dermatitis: from pathomechanisms to immunotoxicology. Exp Dermatol 21, 382-389.

171. Mehl A, Rolinck-Werninghaus C, Staden U, et al. (2006) The atopy patch test in the diagnostic workup of suspected food-related symptoms in children. J Allergy Clin Immunol 118, 923-929.

172. Uter W, Aberer W, Armario-Hita JC, et al. (2012) Current patch test results with the European baseline series and extensions to it from the 'European Surveillance System on Contact Allergy' network, 2007-2008. Contact Dermatitis 67, 9-19.

173. Wassenberg J, Nutten S, Audran R, et al. (2011) Effect of Lactobacillus paracasei ST11 on a nasal provocation test with grass pollen in allergic rhinitis. Clin Exp Allergy 41, $565-573$.
174. Rondon C, Campo P, Togias A, et al. (2012) Local allergic rhinitis: concept, pathophysiology, and management. J Allergy Clin Immunol 129, 1460-1467.

175. Scadding GW, Calderon MA, Bellido V, et al. (2012) Optimisation of grass pollen nasal allergen challenge for assessment of clinical and immunological outcomes. J Immunol Methods 384, 25-32.

176. Carty CL, Heagerty P \& Nakayama K (2006) Inflammatory response after influenza vaccination in men with and without carotid artery disease. Arterioscler Thromb Vasc Biol 26, $2738-2744$.

177. Derosa G, Ferrari I, D'Angelo A, et al. (2009) Oral fat load effects on inflammation and endothelial stress markers in healthy subjects. Heart Vessels 24, 204-210.

178. Kop WJ, Weissman NJ, Zhu J, et al. (2008) Effects of acute mental stress and exercise on inflammatory markers in patients with coronary artery disease and healthy controls. Am J Cardiol 101, 767-773.

179. Wopereis S, Rubingh CM, van Erk MJ, et al. (2009) Metabolic profiling of the response to an oral glucose tolerance test detects subtle metabolic changes. PLoS One 4, e4525.

180. Parks CG, Andrew ME, Blanciforti LA, et al. (2007) Variation in the WBC differential count and other factors associated with reporting of herpes labialis: a population-based study of adults. FEMS Immunol Med Microbiol 51, $336-343$.

181. Pfister R, Sharp SJ, Luben R, et al. (2012) Differential white blood cell count and incident heart failure in men and women in the EPIC-Norfolk study. Eur Heart J33, 523-530.

182. Wikby A, Maxson P, Olsson J, et al. (1998) Changes in CD8 and CD4 lymphocyte subsets, T cell proliferation responses and non-survival in the very old: the Swedish longitudinal OCTO-immune study. Mech Ageing Dev 102, 187-198.

183. Wikby A, Nilsson BO, Forsey R, et al. (2006) The immune risk phenotype is associated with IL- 6 in the terminal decline stage: findings from the Swedish NONA immune longitudinal study of very late life functioning. Mech Ageing Dev 127, 695-704.

184. Minet-Quinard R, Farges MC, Thivat E, et al. (2010) Neutrophils are immune cells preferentially targeted by retinoic acid in elderly subjects. Immun Ageing 7, 10.

185. Varela LM, Ortega A, Bermudez B, et al. (2011) A high-fat meal promotes lipid-load and apolipoprotein B-48 receptor transcriptional activity in circulating monocytes. Am J Clin Nutr 93, 918-925.

186. Walrand S, Farges MC, Dehaese O, et al. (2005) In vivo and in vitro evidences that carotenoids could modulate the neutrophil respiratory burst during dietary manipulation. Eur J Nutr 44, 114-120.

187. Amulic B, Cazalet C, Hayes GL, et al. (2012) Neutrophil function: from mechanisms to disease. Annu Rev Immunol 30, 459-489.

188. Filias A, Theodorou GL, Mouzopoulou S, et al. (2011) Phagocytic ability of neutrophils and monocytes in neonates. BMC Pediatr 11, 29.

189. Flannagan RS, Jaumouille V \& Grinstein S (2012) The cell biology of phagocytosis. Annu Rev Pathol 7, 61-98.

190. Shi C \& Pamer EG (2011) Monocyte recruitment during infection and inflammation. Nat Rev Immunol 11, 762-774.

191. Strunk T, Temming P, Gembruch U, et al. (2004) Differential maturation of the innate immune response in human fetuses. Pediatr Res 56, 219-226.

192. Hughes DA, Wright AJ, Finglas PM, et al. (1997) The effect of beta-carotene supplementation on the immune function of blood monocytes from healthy male nonsmokers. J Lab Clin Med 129, 309-317. 
193. Brtko J, Rock E, Nezbedova P, et al. (2007) Age-related change in the retinoid $\mathrm{X}$ receptor beta gene expression in peripheral blood mononuclear cells of healthy volunteers: effect of 13-cis retinoic acid supplementation. Mech Ageing Dev 128, 594-600.

194. Santos MS, Gaziano JM, Leka LS, et al. (1998) Beta-caroteneinduced enhancement of natural killer cell activity in elderly men: an investigation of the role of cytokines. $\mathrm{Am}$ J Clin Nutr 68, 164-170.

195. Allegra S, Deleine C, Michael-Jubely R, et al. (2006) Implementation of the EGFP-K562 flow cytometric NK test: determination of NK cytotoxic activity in healthy elderly volunteers before and after feeding. Cytometry $A$ 69, 992-998.

196. Biron CA, Nguyen KB, Pien GC, et al. (1999) Natural killer cells in antiviral defense: function and regulation by innate cytokines. Annu Rev Immunol 17, 189-220.

197. Hamerman JA, Ogasawara K \& Lanier LL (2005) NK cells in innate immunity. Curr Opin Immunol 17, 29-35.

198. Konjevic G, Jurisic V, Jovic V, et al. (2012) Investigation of NK cell function and their modulation in different malignancies. Immunol Res 52, 139-156.

199. Lodoen MB \& Lanier LL (2006) Natural killer cells as an initial defense against pathogens. Curr Opin Immunol 18, 391-398.

200. Murphy WJ, Parham P \& Miller JS (2012) NK cells - from bench to clinic. Biol Blood Marrow Transplant 18, S2-S7.

201. Sun JC \& Lanier LL (2011) NK cell development, homeostasis and function: parallels with CD8(+) T cells. Nat Rev Immunol 11, 645-657.

202. Whiteside TL (2001) Measurement of cytotoxic activity of NK/LAK cells. Curr Protoc Immunol Chapter 7, Unit 7.18.

203. Ghanim H, Sia CL, Upadhyay M, et al. (2010) Orange juice neutralizes the proinflammatory effect of a high-fat, highcarbohydrate meal and prevents endotoxin increase and Toll-like receptor expression. Am J Clin Nutr 91, 940-949.

204. Mena MP, Sacanella E, Vazquez-Agell M, et al. (2009) Inhibition of circulating immune cell activation: a molecular antiinflammatory effect of the Mediterranean diet. $\mathrm{Am} \mathrm{J}$ Clin Nutr 89, 248-256.

205. Trombetta ES \& Mellman I (2005) Cell biology of antigen processing in vitro and in vivo. Annu Rev Immunol 23, 975-1028.

206. Rescigno M (2010) Functional specialization of antigen presenting cells in the gastrointestinal tract. Curr Opin Immunol 22, 131-136.

207. Rescigno M \& Di SA (2009) Dendritic cells in intestinal homeostasis and disease. J Clin Invest 119, 2441-2450.

208. Rescigno M \& Chieppa M (2005) Gut-level decisions in peace and war. Nat Med 11, 254-255.

209. Neefjes J, Jongsma ML, Paul P, et al. (2011) Towards a systems understanding of MHC class I and MHC class II antigen presentation. Nat Rev Immunol 11, 823-836.

210. Guermonprez P, Valladeau J, Zitvogel L, et al. (2002) Antigen presentation and $\mathrm{T}$ cell stimulation by dendritic cells. Annu Rev Immunol 20, 621-667.

211. Pascoe MC, Crewther SG, Carey LM, et al. (2011) What you eat is what you are - a role for polyunsaturated fatty acids in neuroinflammation induced depression? Clin Nutr (Edinburgh Scotland) 30, 407-415.

212. Solis-Pereyra B, Aattouri N \& Lemonnier D (1997) Role of food in the stimulation of cytokine production. Am J Clin Nutr 66, 521S-525S.

213. Ouyang W, Rutz S, Crellin NK, et al. (2011) Regulation and functions of the IL-10 family of cytokines in inflammation and disease. Annu Rev Immunol 29, 71-109.
214. Liu Z, Yuan X, Luo Y, et al. (2009) Evaluating the effects of immunosuppressants on human immunity using cytokine profiles of whole blood. Cytokine 45, 141-147.

215. Gonzalez-Navajas JM, Lee J, David M, et al. (2012) Immunomodulatory functions of type I interferons. Nat Rev Immunol 12, 125-135.

216. Viola A \& Luster AD (2008) Chemokines and their receptors: drug targets in immunity and inflammation. Annu Rev Pharmacol Toxicol 48, 171-197.

217. Sallusto F \& Baggiolini M (2008) Chemokines and leukocyte traffic. Nat Immunol 9, 949-952.

218. Sallusto F \& Mackay CR (2004) Chemoattractants and their receptors in homeostasis and inflammation. Curr Opin Immunol 16, 724-731.

219. Hall JA, Cannons JL, Grainger JR, et al. (2011) Essential role for retinoic acid in the promotion of $\mathrm{CD}^{+} \mathrm{T}$ cell effector responses via retinoic acid receptor alpha. Immunity $\mathbf{3 4}$, 435- 447

220. Hamer DH, Sempertegui F, Estrella B, et al. (2009) Micronutrient deficiencies are associated with impaired immune response and higher burden of respiratory infections in elderly Ecuadorians. J Nutr 139, 113-119.

221. Hoyles L \& Vulevic J (2008) Diet, immunity and functional foods. Adv Exp Med Biol 635, 79-92.

222. Maecker HT, McCoy JP \& Nussenblatt R (2012) Standardizing immunophenotyping for the Human Immunology Project. Nat Rev Immunol 12, 191-200.

223. McGuire HM, Vogelzang A, Ma CS, et al. (2011) A subset of interleukin- $21+$ chemokine receptor CCR9 ${ }^{+}$T helper cells target accessory organs of the digestive system in autoimmunity. Immunity 34, 602-615.

224. Rodriguez PC, Quiceno DG \& Ochoa AC (2007) L-Arginine availability regulates T-lymphocyte cell-cycle progression. Blood 109, 1568-1573.

225. Bettelli E, Oukka M \& Kuchroo VK (2007) T(H)-17 cells in the circle of immunity and autoimmunity. Nat Immunol $\mathbf{8}$, 345-350.

226. Duramad P, McMahon CW, Hubbard A, et al. (2004) Flow cytometric detection of intracellular TH1/TH2 cytokines using whole blood: validation of immunologic biomarker for use in epidemiologic studies. Cancer Epidemiol Biomarkers Prev 13, 1452-1458.

227. Jason J \& Larned J (1997) Single-cell cytokine profiles in normal humans: comparison of flow cytometric reagents and stimulation protocols. J Immunol Methods 207, 13-22.

228. Miossec P, Korn T \& Kuchroo VK (2009) Interleukin-17 and type 17 helper T cells. $N$ Engl J Med 361, 888-898.

229. Richard N, Arnold S, Hoeller U, et al. (2011) Hydroxytyrosol is the major anti-inflammatory compound in aqueous olive extracts and impairs cytokine and chemokine production in macrophages. Planta Med 77, 1890-1897.

230. Romagnani S (1994) Lymphokine production by human $\mathrm{T}$ cells in disease states. Annu Rev Immunol 12, 227-257.

231. Maruyama T, Mimura K, Izawa S, et al. (2011) Immunonutritional diet modulates natural killer cell activation and Th17 cell distribution in patients with gastric and esophageal cancer. Nutrition 27, 146-152.

232. Anikeeva N \& Sykulev Y (2011) Mechanisms controlling granule-mediated cytolytic activity of cytotoxic T lymphocytes. Immunol Res 51, 183-194.

233. Issazadeh-Navikas S, Teimer R \& Bockermann R (2012) Influence of dietary components on regulatory $\mathrm{T}$ cells. Mol Med 18, 95-110.

234. Smyth LJ, Starkey C, Vestbo J, et al. (2007) CD4-regulatory cells in COPD patients. Chest 132, 156-163. 
235. Ukena SN, Höpting M, Velaga S, et al. (2011) Isolation strategies of regulatory $\mathrm{T}$ cells for clinical trials: phenotype, function, stability, and expansion capacity. Exp Hematol 39, 1152-1160.

236. Shevach EM (2011) Biological functions of regulatory T cells. Adv Immunol 112, 137-176.

237. Campbell DJ \& Koch MA (2011) Phenotypical and functional specialization of $\mathrm{FOXP}^{+}$regulatory T cells. Nat Rev Immunol 11, 119-130.

238. Bilate $\mathrm{AM} \&$ Lafaille JJ (2012) Induced $\mathrm{CD}^{+}{ }^{+} \mathrm{Foxp}^{+}{ }^{+}$regulatory $\mathrm{T}$ cells in immune tolerance. Annu Rev Immunol 30, 733-758.

239. Sanz I, Wei C, Lee FE, et al. (2008) Phenotypic and functional heterogeneity of human memory B cells. Semin Immunol 20, 67-82.

240. Siekmann JH, Allen LH, Watnik MR, et al. (2003) Titers of antibody to common pathogens: relation to food-based interventions in rural Kenyan schoolchildren. Am J Clin Nutr 77, 242-249.

241. van Riet E, Retra K, Adegnika AA, et al. (2008) Cellular and humoral responses to tetanus vaccination in Gabonese children. Vaccine 26, 3690-3695.

242. Chirumbolo S (2012) Basophil activation test in allergy: time for an update? Int Arch Allergy Immunol 158, 99-114.

243. Beier-Holgersen R \& Brandstrup B (2012) Influence of postoperative enteral nutrition on cellular immunity. A random double-blinded placebo controlled clinical trial. Int J Colorectal Dis 27, 513-520.

244. Jippo T, Kobayashi Y, Sato H, et al. (2009) Inhibitory effects of guarana seed extract on passive cutaneous anaphylaxis and mast cell degranulation. Bioscience 73, 2110-2112.

245. Mondello S, Italiano D, Giacobbe MS, et al. (2010) Glutamine-supplemented total parenteral nutrition improves immunological status in anorectic patients. Nutrition 26, 677-681.

246. Lehuen A \& Novak J (2011) Low numbers and altered phenotype of invariant natural killer $\mathrm{T}$ cells in recurrent varicella zoster virus infection. Cell Immunol 269, 78-81.

247. Larbi A, Franceschi C, Mazzatti D, et al. (2008) Aging of the immune system as a prognostic factor for human longevity. Physiology (Bethesda) 23, 64-74.

248. Degauque N, Boeffard F, Foucher Y, et al. (2011) The blood of healthy individuals exhibits CD8 T cells with a highly altered TCR $\mathrm{Vb}$ repertoire but with an unmodified phenotype. PLoS One 6, e21240.

249. Noh J \& Noh G (2012) Allergen-specific responses of CD19(high) and CD19(low) B cells in non-IgE-mediated food allergy of late eczematous reactions in atopic dermatitis: presence of IL-17- and IL-32-producing regulatory B cells (Br17 \& Br32). Inflamm Allergy Drug Targets 11, 320-329.

250. Emerging Risk FC, Kaptoge S, Di Angelantonio E, et al. (2010) C-reactive protein concentration and risk of coronary heart disease, stroke, and mortality: an individual participant meta-analysis. Lancet 375, 132-140.

251. Erridge C, Attina T, Spickett CM, et al. (2007) A high-fat meal induces low-grade endotoxemia: evidence of a novel mechanism of postprandial inflammation. Am J Clin Nutr 86, 1286-1292.

252. Hingorani AD, Shah T, Casas JP, et al. (2009) C-reactive protein and coronary heart disease: predictive test or therapeutic target? Clin Chem 55, 239-255.

253. Shah T, Newcombe P, Smeeth L, et al. (2010) Ancestry as a determinant of mean population C-reactive protein values: implications for cardiovascular risk prediction. Circ Cardiovasc Genet 3, 436-444.
254. Renault NK, Gaddipati SR, Wulfert F, et al. (2011) Multiple protein extract microarray for profiling human food-specific immunoglobulins A, M, G and E. J Immunol Methods 364, 21-32.

255. Anto JM, Pinart M, Akdis M, et al. (2012) Understanding the complexity of IgE-related phenotypes from childhood to young adulthood: a Mechanisms of the Development of Allergy (MeDALL) seminar. J Allergy Clin Immunol 129, 943-954.

256. Bodtger U, Assing K \& Poulsen LK (2011) A prospective, clinical study on asymptomatic sensitisation and development of allergic rhinitis: high negative predictive value of allergological testing. Int Arch Allergy Immunol 155 289-296.

257. Dekker FW, Mulder Dzn JD, Kramps JA, et al. (1990) The Phadiatop in vitro test for allergy in general practice: is it useful? Fam Pract 7, 144-148.

258. Govaere E, van Gysel D, Verhamme KM, et al. (2009) The association of allergic symptoms with sensitization to inhalant allergens in childhood. Pediatr Allergy Immunol 20, 448-457.

259. Lilja G, Kusoffsky E, Johansson SG, et al. (1995) Screening of atopic allergy in 5-year-old children - a comparison of the diagnostic properties of Phadiatop Paediatric and Phadiatop. Allergy 50, 316-321.

260. Matricardi PM, Nisini R, Biselli R, et al. (1994) Evaluation of the overall degree of sensitization to airborne allergens by a single serologic test: implications for epidemiologic studies of allergy. J Allergy Clin Immunol 93, 68-79.

261. Visness CM, London SJ, Daniels JL, et al. (2009) Association of obesity with IgE levels and allergy symptoms in children and adolescents: results from the National Health and Nutrition Examination Survey 2005-2006. J Allergy Clin Immunol 123, 1163-1169, 1169.e1-1169.e4.

262. Droste JH, Kerhof M, de Monchy JG, et al. (1996) Association of skin test reactivity, specific IgE, total IgE, and eosinophils with nasal symptoms in a community-based population study. The Dutch ECRHS Group. J Allergy Clin Immunol 97, 922-932.

263. Kimmel PL, Phillips TM, Simmens SJ, et al. (1998) Immunologic function and survival in hemodialysis patients. Kidney Int 54, 236-244.

264. Oberbach A, Bluher M, Wirth H, et al. (2011) Combined proteomic and metabolomic profiling of serum reveals association of the complement system with obesity and identifies novel markers of body fat mass changes. $J$ Proteome Res 10, 4769-4788.

265. Matarese G (2000) Leptin and the immune system: how nutritional status influences the immune response. Eur Cytokine Netw 11, 7-14.

266. Mencarelli A, Distrutti E, Renga B, et al. (2011) Probiotics modulate intestinal expression of nuclear receptor and provide counter-regulatory signals to inflammation-driven adipose tissue activation. PLoS One 6, e22978.

267. Lash GE \& Pinto LA (2010) Multiplex cytokine analysis technologies. Expert Rev Vaccines 9, 1231-1237.

268. Richens JL, Urbanowicz RA, Metcalf R, et al. (2010) Quantitative validation and comparison of multiplex cytokine kits. J Biomol Screen 15, 562-568.

269. Molet S, Hamid Q, Davoine F, et al. (2001) IL-17 is increased in asthmatic airways and induces human bronchial fibroblasts to produce cytokines. J Allergy Clin Immunol 108, 430-438.

270. Raj DSC, Shah VO, Rambod M, et al. (2009) Association of soluble endotoxin receptor CD14 and mortality among 
patients undergoing hemodialysis. Am J Kidney Dis $\mathbf{5 4}$ 1062-1071.

271. Clifton PM, Noakes M, Keogh J, et al. (2003) How effective are meal replacements for treating obesity? Asia Pac J Clin Nutr 12, Suppl., S51.

272. Conde J, Scotece M, Gomez R, et al. (2011) Adipokines: biofactors from white adipose tissue. A complex hub among inflammation, metabolism, and immunity. Biofactors 37, 413-420.

273. Conde J, Scotece M, Gómez R, et al. (2010) At the crossroad between immunity and metabolism: focus on leptin. Expert Rev Clin Immunol 6, 801-808.

274. Faggioni R, Feingold KR \& Grunfeld C (2001) Leptin regulation of the immune response and the immunodeficiency of malnutrition. FASEB J 15, 2565-2571.

275. Mackey-Lawrence NM \& Petri WA Jr (2012) Leptin and mucosal immunity. Mucosal Immunol 5, 472-479.

276. Wilk S, Scheibenbogen C, Bauer S, et al. (2011) Adiponectin is a negative regulator of antigen-activated T cells. Eur $J$ Immunol 41, 2323-2332.

277. Wu CJ \& Yu ZR (2004) Effects on blood glucose, insulin, lipid and proatherosclerotic parameters in stable type 2 diabetic subjects during an oral fat challenge. Lipids Health Dis 3, 17.

278. Mortensen OH, Nielsen AR, Erikstrup C, et al. (2009) Calprotectin - a novel marker of obesity. PLoS One 4, e7419.

279. Wassell J (2011) Calprotectin testing in the community. Ann Clin Biochem 48, 1-2.

280. Blum S, Gunzinger A, Muller UR, et al. (2011) Influence of total and specific IgE, serum tryptase, and age on severity of allergic reactions to Hymenoptera stings. Allergy $\mathbf{6 6}$, $222-228$.

281. Ludolph-Hauser D, Rueff F, Fries C, et al. (2001) Constitutively raised serum concentrations of mast-cell tryptase and severe anaphylactic reactions to Hymenoptera stings. Lancet 357, 361-362.

282. Rueff F, Przybilla B, Bilo MB, et al. (2010) Predictors of side effects during the buildup phase of venom immunotherapy for Hymenoptera venom allergy: the importance of baseline serum tryptase. J Allergy Clin Immunol 126, 105-111.

283. van Odijk J, Peterson CG, Ahlstedt S, et al. (2006) Measurements of eosinophil activation before and after food challenges in adults with food hypersensitivity. Int Arch Allergy Immunol 140, 334-341.

284. de Kivit S, Kraneveld AD, Garssen J, et al. (2011) Glycan recognition at the interface of the intestinal immune system: target for immune modulation via dietary components. Eur J Pharmacol 668, Suppl. 1, S124-S132.

285. Gorfu G, Rivera-Nieves J \& Ley K (2009) Role of beta integrins in intestinal lymphocyte homing and retention. Curr Mol Med 9, 836-850.

286. Steck-Scott S, Arab L, Craft NE, et al. (2004) Plasma and lung macrophage responsiveness to carotenoid supplementation and ozone exposure in humans. Eur J Clin Nutr $\mathbf{5 8}$, 1571-1579.

287. Taylor DR (2011) Using biomarkers in the assessment of airways disease. J Allergy Clin Immunol 128, 927-934.

288. van der Top EA, Perry GA \& Gentry-Nielsen MJ (2006) A novel flow cytometric assay for measurement of in vivo pulmonary neutrophil phagocytosis. BMC Microbiol 6, 61.

289. Vatrella A, Bocchino M, Perna F, et al. (2007) Induced sputum as a tool for early detection of airway inflammation in connective diseases-related lung involvement. Respir Med 101, 1383-1389.

290. Eksteen B, Mora JR, Haughton EL, et al. (2009) Gut homing receptors on $\mathrm{CD} 8 \mathrm{~T}$ cells are retinoic acid dependent and not maintained by liver dendritic or stellate cells. Gastroenterology 137, 320-329.

291. Gibson RJ \& Bowen JM (2011) Biomarkers of regimenrelated mucosal injury. Cancer Treat Rev 37, 487-493.

292. Langhorst J, Elsenbruch S, Koelzer J, et al. (2008) Noninvasive markers in the assessment of intestinal inflammation in inflammatory bowel diseases: performance of fecal lactoferrin, calprotectin, and PMN-elastase, CRP, and clinical indices. Am J Gasterenterol 103, 162-169.

293. van Rheenen PF, van de Vijver E \& Fidler V (2010) Faecal calprotectin for screening of patients with suspected inflammatory bowel disease: diagnostic meta-analysis. BMJ 341, c3369.

294. Hanson LA, Bjorkander J \& Oxelius VA (1983) Selective IgA deficiency. In Primary and Secondary Immunodeficiency Disorders, pp. 62-64 [RK Chandra, editor]. Edinburgh: Churchill Livingstone.

295. Daele J \& Zicot AF (2000) Humoral immunodeficiency in recurrent upper respiratory tract infections. Some basic, clinical and therapeutic features. Acta Otorbinolaryngol Belg 54, 373-390.

296. Bishop NC \& Gleeson M (2009) Acute and chronic effects of exercise on markers of mucosal immunity. Front Biosci 14, $4444-4456$.

297. Costa C, Rufino R, Traves SL, et al. (2008) CXCR3 and CCR5 chemokines in induced sputum from patients with COPD. Chest 133, 26-33.

298. Hacievliyagil SS, Gunen H, Mutlu LC, et al. (2006) Association between cytokines in induced sputum and severity of chronic obstructive pulmonary disease. Respir Med 100, 846-854.

299. Klinder A, Karlsson PC, Clune Y, et al. (2007) Fecal water as a non-invasive biomarker in nutritional intervention: comparison of preparation methods and refinement of different endpoints. Nutr Cancer 57, 158-167.

300. Long KZ, Garcia C, Ko G, et al. (2011) Vitamin A modifies the intestinal chemokine and cytokine responses to norovirus infection in Mexican children. J Nutr 141, 957-963.

301. Mai V, McCrary QM, Sinha R, et al. (2009) Associations between dietary habits and body mass index with gut microbiota composition and fecal water genotoxicity: an observational study in African American and Caucasian American volunteers. Nutr J 8, 49.

302. Oberreuther-Moschner DL, Jahreis G, Rechkemmer G, et al. (2004) Dietary intervention with the probiotics Lactobacillus acidophilus 145 and Bifidobacterium longum 913 modulates the potential of human faecal water to induce damage in HT29clone19A cells. Br J Nutr 91, 925-932.

303. Rechkemmer G, Schnaebele K, Bub A, et al. (2002) Use of fecal water as a biomarker in dietary intervention studies. J Nutr 132, 3537 S.

304. Woods JA, Dunne C, Collins JK, et al. (2002) Genotoxicity of fecal water in a free-living Irish population. Nutr Cancer 42, 62-69.

305. Di Pierro F, Spinelli G, Monsu G, et al. (2011) Clinical effectiveness of a highly standardized and bioavailable mixture of flavonoids and triterpenes in the management of acute hemorroidal crisis. Acta Biomedica 82, 35-40.

306. Hamer HM, Jonkers DMAE, Renes IB, et al. (2010) Butyrate enemas do not affect human colonic MUC2 and TFF3 expression. Eur J Gastroenterol Hepatol 22, 1134-1140.

307. Linden SK, Sutton P, Karlsson NG, et al. (2008) Mucins in the mucosal barrier to infection. Mucosal Immunol $\mathbf{1}$, 183-197. 